\title{
Effect of hydrogen on the fatigue crack growth rate of quenched and tempered CrMo and CrMoV steels
}

\author{
L.B. Peral ${ }^{1, *}$, A. Zafra ${ }^{1}$, S. Blasón ${ }^{1}$, C.Rodríguez ${ }^{1}$ and J.Belzunce ${ }^{1}$ \\ ${ }^{1}$ Polytechnic Engineering School, University of Oviedo, campus universitario, 33203 Gijón, Spain
}

\begin{abstract}
In order to select the most appropriate steel to deal with pressurized hydrogen over long periods of time, the fatigue crack propagation rate of quenched and tempered $\mathrm{CrMo}$ and $\mathrm{CrMoV}$ steel grades was assessed by means of tests performed on thermally pre-charged specimens in a hydrogen reactor at 195 bar and $450^{\circ} \mathrm{C}$ during 21 hours. Cylindrical samples were used to measure the hydrogen content and their desorption kinetics at room temperature and compact tensile specimens to determine the fatigue crack growth rate. Under the aforementioned pre-charging conditions, significant amounts of hydrogen were introduced, being much larger in the CrMoV steel grades, which also have much lower apparent diffusion coefficients, as precipitation of fine vanadium carbides during tempering provides strong hydrogen traps. Moreover, the fatigue crack growth rate increased significantly due to the presence of internal hydrogen in the CrMo grades for test frequencies lower than $10 \mathrm{~Hz}$ in comparison with tests performed in air. Furthermore, the presence of vanadium carbides in the CrMoV steel significantly improved fatigue crack growth performance, the effective hydrogen diffusion distance per cycle and the hydrogen concentration in the process zone ahead of the advancing crack being considerably reduced.
\end{abstract}

Keywords: hydrogen embrittlement, structural steels, fatigue crack growth rate, diffusion coefficient.

\section{Introduction}

For the development of infrastructures such as hydrogen tanks, pipes and valves for the impending new hydrogen society, a certain number of pressing technical problems must first be solved. It is necessary to understand the complex embrittlement phenomena that take place when hydrogen diffuses into these metallic components submitted to static and cyclic mechanical loads in the presence of manufacturing defects. Vessels used to store and transport hydrogen must be able to provide safe service conditions over long periods of time in direct contact with gaseous hydrogen under high internal pressure, it being especially crucial to ensure good resistance to hydrogen embrittlement. The use of quenched and tempered steels alloyed with chrome, chrome-molybdenum, nickel-chromium-molybdenum or chrome-molybdenumvanadium is generally a good option in these industrial installations [1]. In this context, high yield strength steels are preferred in order to reduce the vessel wall thickness, although it is well known that these steels are more sensitive to hydrogen embrittlement $[2,3,4]$. Components of this kind are subjected to important cyclic loads produced by high hydrogen pressures (up to 70 or even $100 \mathrm{MPa}$ ) over at least 15 years and safe service conditions must be guaranteed throughout this period [5,6,7]. For this reason, it is important to know how hydrogen diffuses and accumulates in the process zone existing ahead of any possible defect until reaching a critical concentration, which could trigger the failure of the component or crack initiation and growth in specific locations of the component.

An important task for material scientists and engineers is the development of materials capable of withstanding the effects of cyclic loading in hydrogen environments. Comprehensive, detailed studies quantifying the influence of hydrogen on fatigue crack growth rate are still needed in order to produce components able to perform satisfactorily in services for up to 15 years under high hydrogen pressures, there currently being an urgent need to produce reliable data on the fatigue behaviour of candidate materials in hydrogen environments.

In order to simulate the interaction between hydrogen atoms and the steel microstructure, there are two basic ways to analyse the effects of hydrogen in the mechanical properties of steels: testing in high-pressure hydrogen gas (external hydrogen), and testing in air after pre-charging the specimens in a hydrogenated 
medium (internal hydrogen) [5]. In the case of external hydrogen provided by high hydrogen pressures, the measurement of mechanical properties requires the use of unique, expensive facilities as material test specimens are exposed to high-pressure hydrogen gas while simultaneously being subjected to specific mechanical loads. However, specimens can be easily and conveniently pre-charged at high temperature from a gaseous atmosphere (as hydrogen diffusion depends exponentially on temperature, the use of high temperatures strongly accelerates pre-charging, thus providing high hydrogen contents after relatively low charging times) or electrochemically from an aqueous solution at room temperature.

Several studies testing specimens in high-pressure hydrogen gas have been performed in recent years. Yamabe et al. [8] compared the fatigue crack growth rate (FCGR) of a quenched and tempered CrMo steel $\left(\sigma_{\text {uts }}=870 \mathrm{MPa}\right)$ in air and in gaseous hydrogen. These authors show that hydrogen pressure does not affect the fatigue crack growth rate at $\Delta \mathrm{K}<10 \mathrm{MPa} \sqrt{m}$, although an important acceleration of this rate was seen at higher $\Delta \mathrm{K}$ values. The onset of this mode occurs above a critical $\mathrm{K}^{\mathrm{T}}$ max value [5], in line with the superposition of hydrogen-assisted sustained-load (or static load) crack growth onto mechanical fatigue crack propagation. Similar results were also obtained by other researchers using different structural steels [9,10,11,12]. Tazoe et al. [13] very recently conducted $\Delta \mathrm{K}$ decreasing tests to investigate the fatigue threshold of a CrMo steel in a $9 \mathrm{MPa}$ hydrogen gas environment, concluding that the fatigue crack growth rate in the near-threshold region in hydrogen gas was comparable to that in air. The aforementioned authors $[9,10,11,12]$ and also $[14,15,16]$ have also observed fatigue crack growth rate increases of at least one order of magnitude when specimens are loaded in gaseous hydrogen at $\Delta K>10 \mathrm{MPa} \sqrt{m}$ under low test frequencies $(0.1$ and $1 \mathrm{~Hz})$ in comparison with tests performed at room temperature in air, while crack growth acceleration was much lower or even non-significant at high frequencies.

As to internal hydrogen, it may should be borne in mind that thermal pre-charging of steel specimens in hydrogen atmospheres may be limited to $450^{\circ} \mathrm{C}$ and 48 hours to completely avoid the methane reaction, which is the reaction between hydrogen atoms and solute carbon to produce a methane molecule [17]. Thermal pre-charging was respectively employed in [18] and [19] under a hydrogen pressure of $100 \mathrm{MPa}$ at $85^{\circ} \mathrm{C}$ for $200-240 \mathrm{~h}$ to charge $0.33 \mathrm{ppm}$ hydrogen in a quenched and tempered Ni-Cr-Mo steel $\left(\sigma_{\mathrm{ys}}=754\right.$ $\mathrm{MPa})$ and $2 \mathrm{ppm}$ hydrogen in a quenched and tempered SAE52100 steel ( $\left.\sigma_{\mathrm{ys}}=1794 \mathrm{MPa}\right)$. The effects of hydrogen on the fatigue crack growth rate observed by these authors using hydrogen pre-charged specimens were similar to those of specimens exposed to external hydrogen: fatigue crack growth acceleration due to the presence of hydrogen strongly depending on the frequency under $\Delta \mathrm{K}$ values of $20-40 \mathrm{MPa} \sqrt{\mathrm{m}}$. Other researchers $[20,21]$ have also used electrochemically hydrogen pre-charged specimens of low-alloy CrMo steels to show fatigue crack growth rate enhancement resulting from the presence of internal hydrogen and the strong influence of the applied frequency or hold time.

In the present study, gaseous hydrogen pre-charging at high temperature was employed. In this way, given the exponential variation of the diffusion coefficient and solubility with temperature, the kinetics of hydrogen entry into the steel can be significantly accelerated, achieving a similar concentration of hydrogen to that obtained after years of service at room temperature within only a few hours. However, the main drawback of this technique is the need to carry out the mechanical tests just after the hydrogen pre-charge in order to limit its desorption. Compact specimens of quenched and tempered $\mathrm{CrMo}$ and $\mathrm{CrMoV}$ steels were thermally pre-charged with hydrogen, following which fatigue crack propagation rates were determined. The hydrogen content after pre-charging and the desorption kinetics were also determined. The influence of frequency on the fatigue crack growth rate was likewise studied. Finally, scanning electron microscopy (SEM) was used to analyse the failure micromechanisms of the steels.

\section{Experimental procedure}

\subsection{Materials and heat treatments}

Three different low-alloyed ferritic steels belonging to the Cr-Mo family were selected in this study, one of which was alloyed with vanadium. The chemical compositions of the $42 \mathrm{CrMo} 4,2.25 \mathrm{Cr} 1 \mathrm{Mo}$ and 2.25Cr1MoV steels are shown in Table 1. 
Table 1. Chemical composition (weight \%).

\begin{tabular}{|c|c|c|c|c|c|c|}
\hline Steel & $\mathrm{C}$ & $\mathrm{Mn}$ & $\mathrm{Si}$ & $\mathrm{Cr}$ & $\mathrm{Mo}$ & $\mathrm{V}$ \\
\hline 42CrMo4 & 0.42 & 0.62 & 0.18 & 0.98 & 0.22 & - \\
\hline $2.25 \mathrm{Cr} 1 \mathrm{Mo}$ & 0.14 & 0.56 & 0.16 & 2.23 & 1 & - \\
\hline $2.25 \mathrm{Cr} 1 \mathrm{MoV}$ & 0.15 & 0.52 & 0.09 & 2.27 & 1 & 0.3 \\
\hline
\end{tabular}

The 2.25Cr1Mo and 2.25Cr1MoV steels were first studied in the as-received (AR), quenched and tempered condition (see Table 2). In order to obtain other different steel qualities, the 2.25Cr1Mo steel was austenitized at $940^{\circ} \mathrm{C}$ for $30 \mathrm{~min}$, quenched in water and tempered at $600^{\circ} \mathrm{C}$ for two hours. As regards the $2.25 \mathrm{Cr} 1 \mathrm{MoV}$ steel, this was austenitized at $925^{\circ} \mathrm{C}$ for $90 \mathrm{~min}$, quenched in water and tempered at $650^{\circ} \mathrm{C}$ for two hours. Finally, the $42 \mathrm{CrMo} 4$ steel, received in a normalizing condition (AR), was austenitized at $845^{\circ} \mathrm{C}$ for $40 \mathrm{~min}$, quenched in water and respectively tempered at 700 and at $650^{\circ} \mathrm{C}$ for two hours. Thus, two different grades of each steel were studied. The sequence of heat treatments and the nomenclature of all the studied grades (based on the tempering temperature) are given in Table 2.

Table 2. Heat treatments.

\begin{tabular}{|c|c|}
\hline Steel grade & Heat treatment sequences \\
\hline 42CrMo4 & AR: Normalizing treatment \\
\hline 42CrMo4_700 & $\mathrm{AR}+845^{\circ} \mathrm{C} / 40 \mathrm{~min}+$ water quenching $+700^{\circ} \mathrm{C} / 2 \mathrm{~h}$ tempering \\
\hline 42CrMo4_650 & $\mathrm{AR}+845^{\circ} \mathrm{C} / 40 \mathrm{~min}+$ water quenching $+650^{\circ} \mathrm{C} / 2 \mathrm{~h}$ tempering \\
\hline 2.25Cr1Mo_690 & $\mathrm{AR}: 940^{\circ} \mathrm{C} / 3 \mathrm{~h}+$ water quenching $+690^{\circ} \mathrm{C} / 30 \mathrm{~h}$ tempering \\
\hline 2.25Cr1Mo_600 & $\mathrm{AR}+940^{\circ} \mathrm{C} / 30 \mathrm{~min}+$ water quenching $+600^{\circ} \mathrm{C} / 2 \mathrm{~h}$ tempering \\
\hline 2.25Cr1MoV_720 & $\mathrm{AR}: 925^{\circ} \mathrm{C} / 30 \mathrm{~min}+$ water quenching $+720^{\circ} \mathrm{C} / 3 \mathrm{~h}$ tempering \\
\hline 2.25Cr1MoV_650 & $\mathrm{AR}+925^{\circ} \mathrm{C} / 90 \mathrm{~min}+$ water quenching $+650^{\circ} \mathrm{C} / 2 \mathrm{~h}$ tempering \\
\hline
\end{tabular}

Different specimens were machined to perform the different tests: small cylindrical samples to measure hydrogen contents and the kinetics of hydrogen egression at room temperature (RT), and tensile as well as compact tensile (CT) specimens for fatigue crack growth testing.

\subsection{Hydrogen pre-charging}

All the specimens were pre-charged with gaseous hydrogen in a high-pressure hydrogen reactor. In order to ensure that all the specimens were saturated with hydrogen (the maximum thickness of specimens was 10 $\mathrm{mm}$ ), the following conditions were applied: 21 hours at $450^{\circ} \mathrm{C}$ under a pressure of $19.5 \mathrm{MPa}$ of pure hydrogen.

The high temperature hydrogen solubility of the quenched and tempered $2.25 \mathrm{Cr} 1 \mathrm{Mo}$ and $2.25 \mathrm{Cr} 1 \mathrm{MoV}$ steels was respectively calculated using expressions (1) and (2) reported by Pillot [17]

$$
\begin{aligned}
& \mathrm{C}_{\mathrm{H}}=0.152 \cdot \exp (-27079 / \mathrm{R} \cdot \mathrm{T}) \cdot \sqrt{P} \\
& \mathrm{C}_{\mathrm{H}}=9.23 \cdot 10^{-3} \cdot \exp (-6943 / \mathrm{R} \cdot \mathrm{T}) \cdot \sqrt{P}
\end{aligned}
$$

where $C_{H}$ represents the hydrogen content expressed in 'mass ppm', $\mathrm{R}$ is the gas constant $(8.31 \mathrm{~J} / \mathrm{mol} \cdot \mathrm{K}), \mathrm{T}$ is the temperature $(\mathrm{K})$ and $\mathrm{P}$ the hydrogen pressure $(\mathrm{Pa})$. Applying these equations to the hydrogen charging conditions employed in this study $\left(19.5 \mathrm{MPa}\right.$ and $\left.450^{\circ} \mathrm{C}\right)$, hydrogen contents of 7.4 and $13 \mathrm{ppm}$ were respectively introduced into the $2.25 \mathrm{Cr} 1 \mathrm{Mo}$ and $2.25 \mathrm{Cr} 1 \mathrm{MoV}$ steel samples.

As regards the $42 \mathrm{CrMo} 4$ steel, the lattice hydrogen content of BCC iron reported by Hirtz [24] was used, Equation (3), considering that traps are not active at this high temperature 


$$
\mathrm{C}_{\mathrm{H}}=104.47 \cdot \sqrt{f} \cdot \exp (-28600 / \mathrm{RT})
$$

where f represents the fugacity in MPa. According to San Marchi [25], fugacity can be expressed from the hydrogen pressure, $p$, according to equation 4 :

$$
f=p \cdot e^{(b p / R T)}
$$

where $b$ is a constant of value 15.84 , and the pressure, $p$, is expressed in MPa.

Applying these equations to our hydrogen charging conditions, a hydrogen content of $4.1 \mathrm{ppm}$ was introduced into the samples of the $42 \mathrm{CrMo} 4$ steel.

After the 21 hours of maintenance of the specimens in the hydrogen reactor, a cooling phase of $1 \mathrm{~h}$, until reaching a temperature of $85^{\circ} \mathrm{C}$ was always necessary to allow specimens to be removed from the reactor. Although hydrogen pressure was maintained during cooling, the decrease in temperature creates a thermodynamic driving force for hydrogen egress from the specimens, leading to a significant hydrogen loss in all cases. The hydrogen pre-charged specimens were then removed from the reactor and rapidly immersed in liquid nitrogen $\left(-196^{\circ} \mathrm{C}\right)$, where they were kept until the moment of testing, in order to avoid additional hydrogen losses.

\subsection{Desorption curves}

The amount of hydrogen absorbed by the different steel grades was determined and the hydrogen desorption curves at room temperature were plotted. The hydrogen content was measured by means of thermal desorption analysis (TDA) on a LECO DH603 hydrogen analyzer, which is able to measure hydrogen concentrations between 0.1 and $2500 \mathrm{ppm}$. The equipment's measuring principle is based on the difference in thermal conductivity between a reference gas flow of pure nitrogen and a secondary flow composed of nitrogen and the hydrogen thermally extracted from the sample kept at $1100^{\circ} \mathrm{C}$ for $400 \mathrm{~s}$. Cylindrical steel pins of $10 \mathrm{~mm}$ in diameter and $30 \mathrm{~mm}$ long $(\approx 20 \mathrm{~g})$ were used for this purpose. After extraction from the liquid nitrogen and before the measurement was performed, each pin was submerged in an ultrasonic bath with acetone for 5 minutes and carefully dried using cold air. Hydrogen content measurements were conducted just after pre-charging to determine the total hydrogen present in the steel at the start of the different tests, and also after different hold times at room temperature until only the strongly trapped hydrogen remained (residual hydrogen) to determine, in this case, the hydrogen desorption curves (hydrogen evolution over time at room temperature).

\subsection{Hydrogen diffusion coefficient estimation}

Fitting the experimentally measured hydrogen desorption data was used to estimate the apparent hydrogen diffusion coefficient $\left(\mathrm{D}_{\text {app }}\right)$ of the six steel grades. An axisymmetric bi-dimensional diffusion analysis of the cylindrical samples was performed using a commercial FEM software (Abaqus Cae) employing 4 node linear axisymmetric quadrilateral elements (Figure 1). The initial hydrogen content experimentally determined at the end of the cooling phase (from 450 to $85^{\circ} \mathrm{C}$ in the high pressure reactor) by means of the LECO analyser was taken as the first point of the analysis (boundary condition 1 or BC1). The residual hydrogen content, likewise determined using the LECO analyser after a long stay at room temperature, was taken as our surface condition (boundary condition 2, BC2).

Fick's diffusion law ( $J=-D_{\text {app }} \nabla C_{L}$, $J$ being the hydrogen flux, $D_{\text {app }}$ the apparent diffusion coefficient, and $C_{L}$ representing the lattice hydrogen concentration) was applied to a cylinder with a radius (R) of $5 \mathrm{~mm}$ varying the apparent diffusion coefficient, $\mathrm{D}_{\text {app, }}$ and the hydrogen evolution over time at room temperature was calculated (only radial diffusion was considered). The diffusion coefficient which best fitted the experimental data was taken as the apparent diffusion coefficient of the steel 


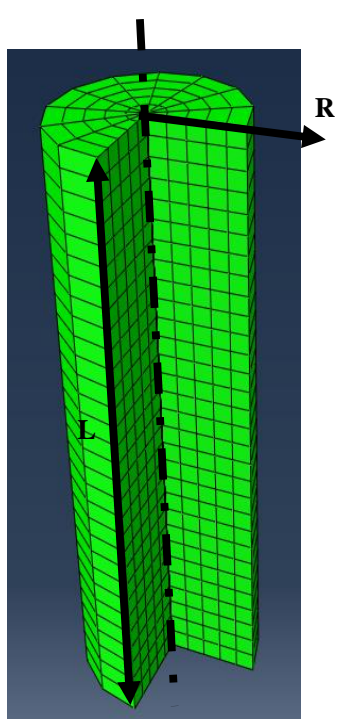

(a)

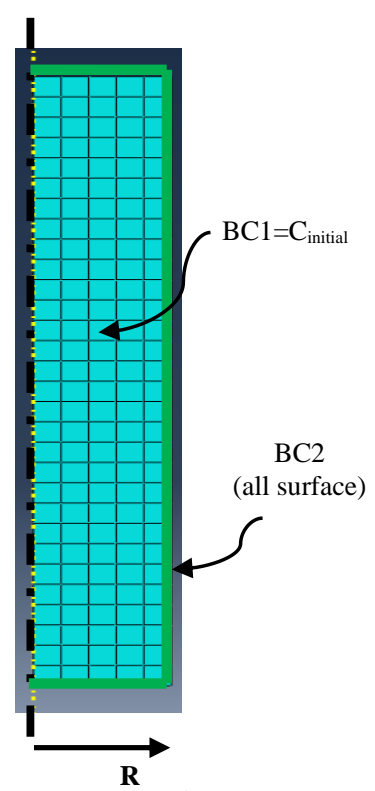

(b)



(c)

Figure 1. Simulated sample (a) and boundary conditions (b) used in radial hydrogen desorption at room temperature (c). Hydrogen pre-charged samples with radius $\mathrm{R}=5 \mathrm{~mm}$ and length $\mathrm{L}=30 \mathrm{~mm}$.

\subsection{Mechanical testing}

\subsubsection{Tensile tests}

Tensile tests were performed in air on smooth specimens with a diameter of $5 \mathrm{~mm}$ and a calibrated length of $28 \mathrm{~mm}$ on an Instron 5582 tensile testing machine under a displacement rate of $0.4 \mathrm{~mm} / \mathrm{min}$.

\subsubsection{Fatigue crack growth tests}

The fatigue crack growth rate was determined using compact tensile CT specimens with a width of $48 \mathrm{~mm}$ and a thickness of $10 \mathrm{~mm}$ (see Figure 2). Before hydrogen pre-charging, the specimens were first fatigue precracked at $\mathrm{R}=0.1$ and $10 \mathrm{~Hz}$ until obtaining an initial crack length versus width ratio $\mathrm{a} / \mathrm{W}=0.2$, following the ASTM E647 standard [22].

In order to determine the fatigue behaviour of each steel grade without internal hydrogen, uncharged CT specimens were fatigue tested at room temperature, under a load ratio $\mathrm{R}=0.1$ and a frequency of $10 \mathrm{~Hz}$.

Fatigue crack growth tests were then performed on hydrogen pre-charged specimens. All the tests were carried out in air, at room temperature, under a load ratio $\mathrm{R}=0.1$. Test frequencies of $10,1,0.5,0.1$, and even 0.05 were used in some cases in order to assess the influence of this parameter on the fatigue crack growth rate. The initial applied $\Delta \mathrm{K}$ was around $25-35 \mathrm{MPa} \sqrt{m}$ in all cases.

Crack length was continuously monitored by means of a CTOD extensometer, allowing the curves representing crack growth rate $(\mathrm{da} / \mathrm{dN})$ versus stress intensity factor range $(\Delta \mathrm{K})$ to be obtained. 

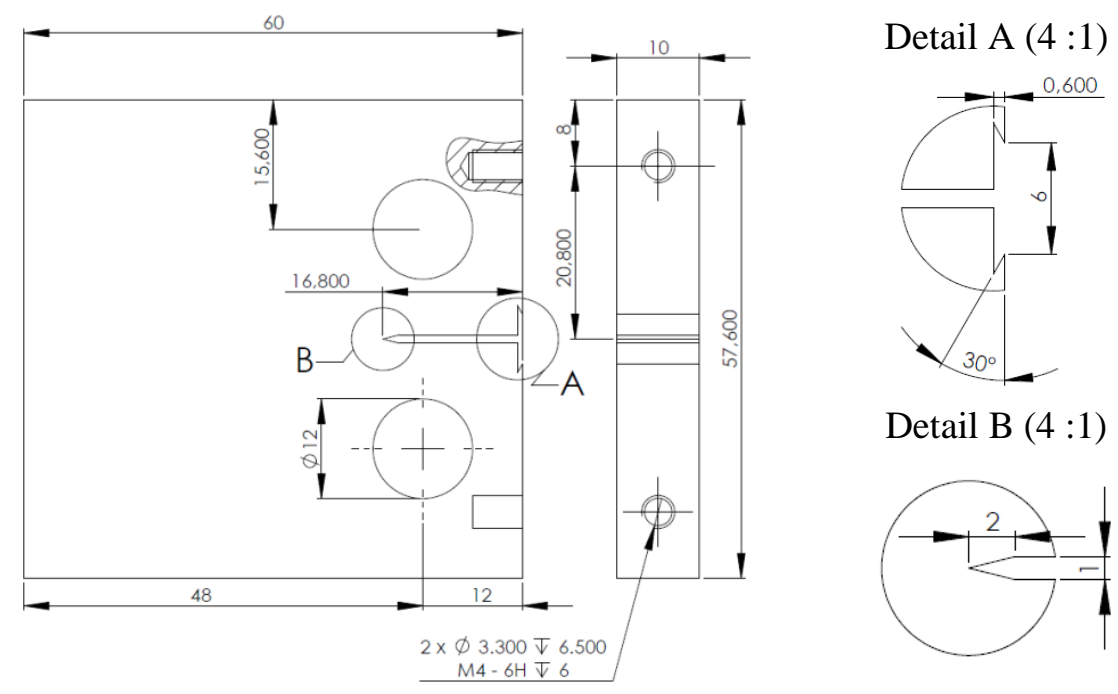

Detail B $(4: 1)$

Figure 2. Geometry and dimensions (mm) of CT specimens.

\subsection{Observation of microstructures and fracture surfaces}

The steel microstructures were observed under a scanning electron microscope (SEM JEOL-JSM5600) using an acceleration voltage of $20 \mathrm{kV}$ (the samples were previously ground and finally polished with $1 \mu \mathrm{m}$ diamond paste and etched with Nital-2\%). The fracture surfaces of the fatigue-tested specimens were also carefully examined using the same technique.

\section{Results}

\subsection{Steel microstructures and tensile properties}

The microstructures of the $42 \mathrm{CrMo} 4,2.25 \mathrm{Cr} 1 \mathrm{Mo}$ and $2.25 \mathrm{Cr} 1 \mathrm{MoV}$ steels after the different heat treatments are shown in Figure 3.

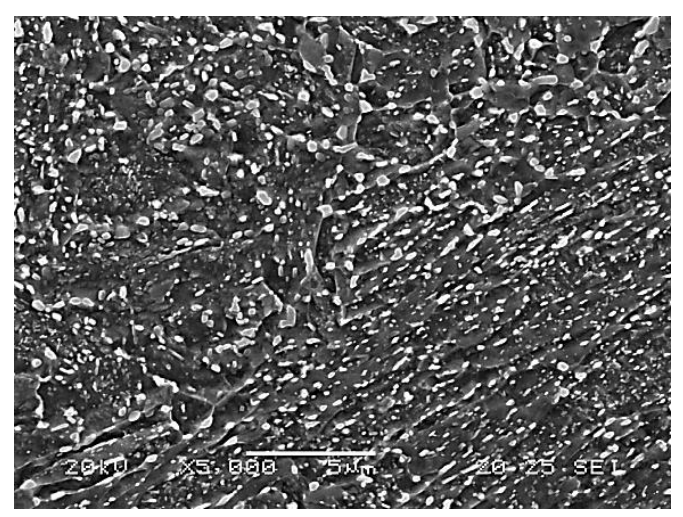

(a) 42CrMo4_700

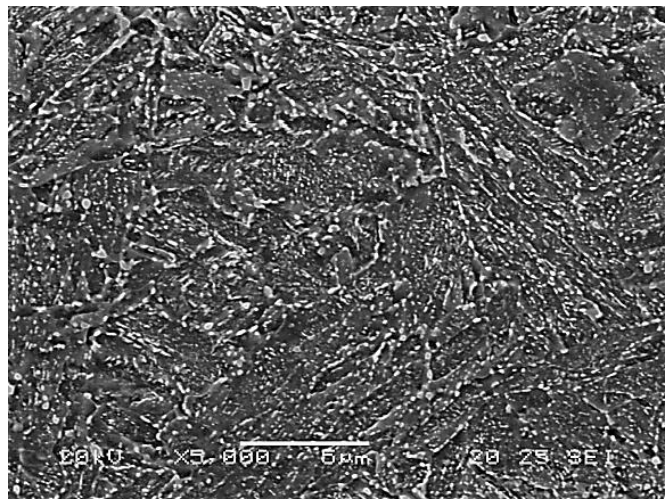

(b) 42CrMo4_650 




(c) $2.25 \mathrm{Cr} 1 \mathrm{Mo} 690$

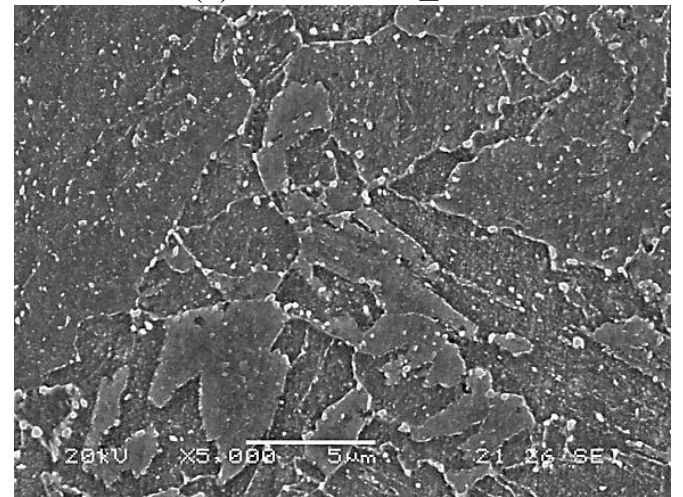

(e) $2.25 \mathrm{Cr} 1 \mathrm{Mo} 0.3 \mathrm{~V} \_720$

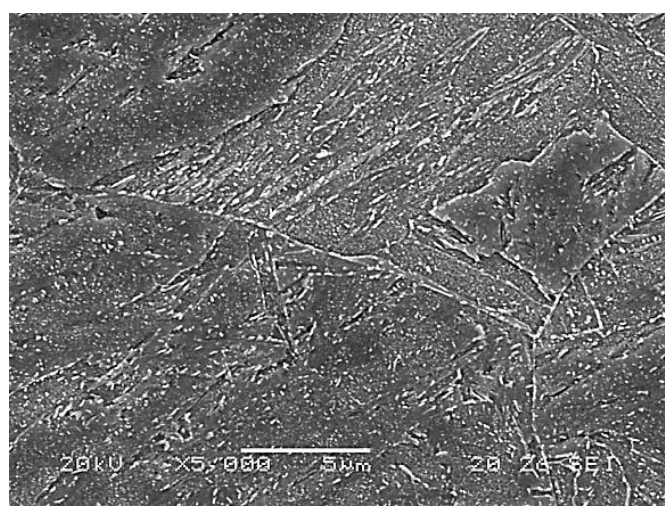

(d) $2.25 \mathrm{Cr} 1 \mathrm{Mo} 600$

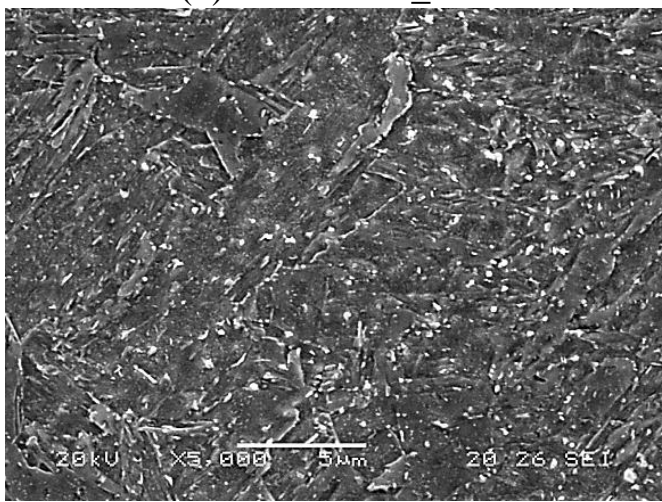

(f) $2.25 \mathrm{Cr} 1 \mathrm{Mo} 0.3 \mathrm{~V} \_650$

Figure 3. Microstructure of the steel grades, SEM. 5000x.

The obtained microstructures were in all cases tempered martensite, in which the profuse carbide precipitation that takes place during the tempering process can be clearly seen. Martensite internal residual stresses relax, dislocation re-arrangement/annihilation and substructure recovery takes place, and elongated carbides precipitated in martensite block and packet boundaries break up, globulize and finally grow to yield a more uniform distribution with increasing tempering temperature [23].

The aforementioned microstructural differences give rise to the hardness and tensile properties listed in Table 3. As expected, yield strength, $\sigma_{y s}$, ultimate tensile strength, $\sigma_{\text {uts }}$ and Brinell hardness, HB, progressively decrease with increasing tempering temperature, while the opposite occurs with tensile elongation, e, and reduction in area, RA.

Table 3. Hardness and tensile properties of the different steel grades at RT in air.

\begin{tabular}{|c|c|c|c|c|c|c|}
\hline Steel Grades & Heat treatment & $\begin{array}{c}\sigma_{\text {ys }} \\
{[\mathrm{MPa}]}\end{array}$ & $\begin{array}{c}\sigma_{\text {uts }} \\
{[\mathrm{MPa}]}\end{array}$ & $\begin{array}{c}\mathrm{e} \\
{[\%]}\end{array}$ & $\begin{array}{c}\text { RA } \\
{[\%]}\end{array}$ & HB \\
\hline 42CrMo4_700 & $845^{\circ} \mathrm{C}+\mathrm{WQ}+\mathrm{T} 700^{\circ} \mathrm{C} / 2 \mathrm{~h}$ & 622 & 710 & 22 & 61 & 201 \\
\hline 42CrMo4_650 & $845^{\circ} \mathrm{C}+\mathrm{WQ}+\mathrm{T} 650^{\circ} \mathrm{C} / 2 \mathrm{~h}$ & 820 & 905 & 16 & 57 & 246 \\
\hline $2.25 \mathrm{Cr} 1 \mathrm{Mo} \_690$ & $940^{\circ} \mathrm{C}+\mathrm{WQ}+\mathrm{T} 690^{\circ} \mathrm{C} / 30 \mathrm{~h}$ & 430 & 580 & 27 & 72 & 170 \\
\hline $2.25 \mathrm{Cr} 1 \mathrm{Mo} \_600$ & $940^{\circ} \mathrm{C}+\mathrm{WQ}+\mathrm{T} 600^{\circ} \mathrm{C} / 2 \mathrm{~h}$ & 761 & 887 & 19 & 75 & 285 \\
\hline $2.25 \mathrm{Cr} 1 \mathrm{MoV} \_720$ & $925^{\circ} \mathrm{C}+\mathrm{WQ}+\mathrm{T} 720^{\circ} \mathrm{C} / 3 \mathrm{~h}$ & 567 & 714 & 20 & 80 & 200 \\
\hline 2.25Cr1MoV_650 & $925^{\circ} \mathrm{C}+\mathrm{WQ}+\mathrm{T} 650^{\circ} \mathrm{C} / 2 \mathrm{~h}$ & 667 & 829 & 20 & 75 & 262 \\
\hline
\end{tabular}




\subsection{Hydrogen desorption curves and diffusion coefficient estimation}

The hydrogen desorption data experimentally obtained at room temperature for each steel grade are shown in Figure 4 along with the fitted FEM simulated curves. These figures represent the evolution of the hydrogen content (ppm) versus the exposure time in air (hours) at room temperature.

The initial hydrogen content, $\mathrm{C}_{\mathrm{H} 0}$, corresponds to the first point of the desorption curve (hydrogen content at the end of the cooling phase following thermal pre-charging in the reactor, $\mathrm{BC} 1$ in Figure 1). The residual hydrogen, $\mathrm{C}_{\mathrm{Hf}}$, is the hydrogen strongly trapped in the steel microstructure, i.e. the hydrogen content after a long exposure at room temperature (BC2 in Figure 1). The diffusible hydrogen, described as the amount of hydrogen that is able to overcome traps and diffuse out of the steel when sufficient time is available, was calculated as the difference between the initial and final hydrogen contents $\left(\mathrm{C}_{\mathrm{H} 0}-\mathrm{C}_{\mathrm{Hf}}\right)$.

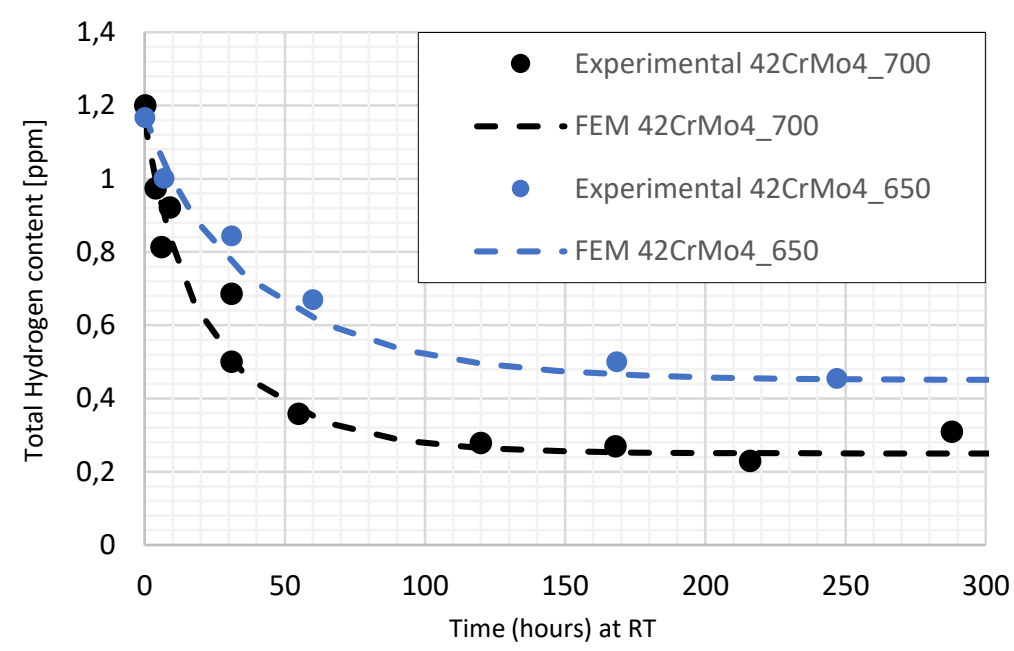

(a)

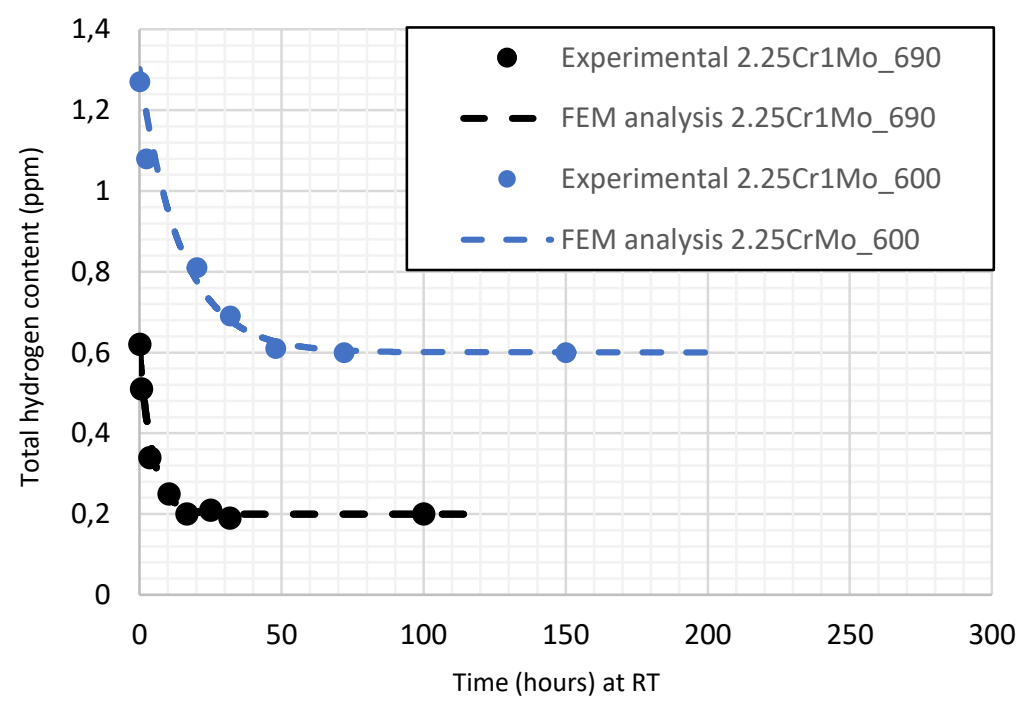

(b) 


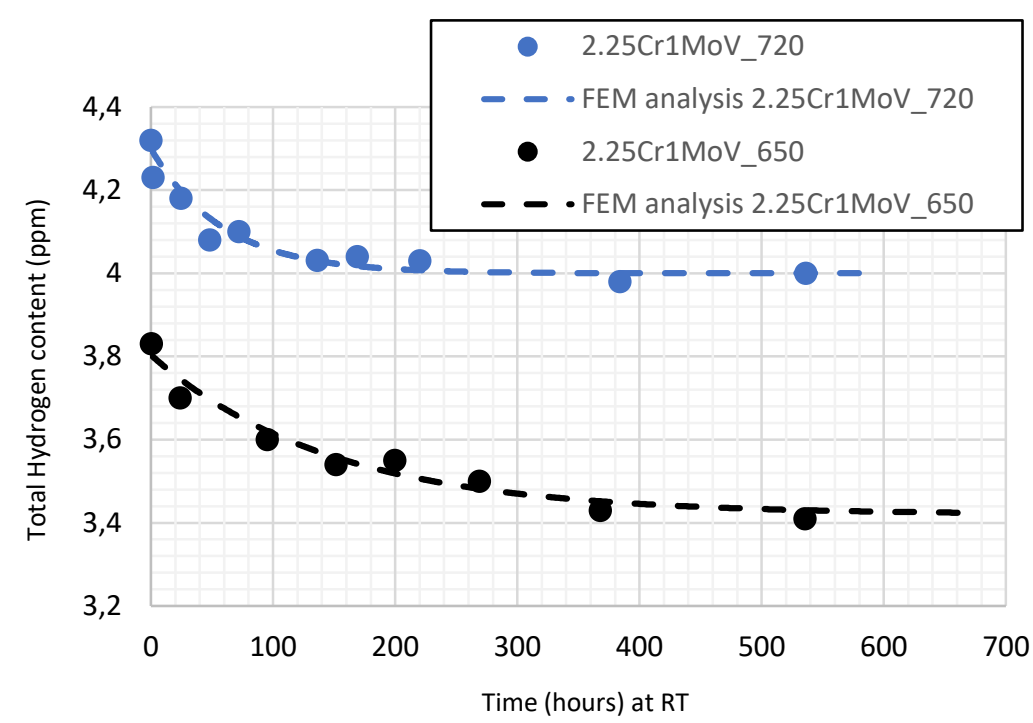

(c)

Figure 4. Hydrogen desorption curves. Experimental data (points) and numerical fit (line).

(a) $42 \mathrm{CrMo} 4$, (b) $2.25 \mathrm{Cr} 1 \mathrm{Mo}$ and (c) $2.25 \mathrm{Cr} 1 \mathrm{MoV}$

As previously stated, data fitting of the experimentally measured hydrogen desorption curves was used to estimate the apparent hydrogen diffusion coefficient, $\mathrm{D}_{\mathrm{app}}$, in the different steel grades. As an example, based on the procedure described in Figure 1c, the initial hydrogen distribution at the end of the cooling phase (from 450 to $85^{\circ} \mathrm{C}$ performed in the high pressure reactor) in the case of the 2.25Cr1Mo_690 steel is shown in Figure 5b. This hydrogen distribution corresponds to the first data point of the desorption curve (Figure 4b), where an average hydrogen content of $0.6 \mathrm{ppm}$ was experimentally measured. However, the specimen surface retains the residual hydrogen content $(0.2$ ppm in this grade of steel which represents our surface boundary condition, denoted as BC2) and hydrogen contents as high as $1.15 \mathrm{ppm}$ are still present in the centre of the specimen. Figure $5 \mathrm{c}$ corresponds to the final or residual hydrogen content $(0.2 \mathrm{ppm}$ in this steel grade $)$ which was experimentally measured after a sufficiently long hold time at room temperature. The diffusion coefficient which provides the best fit to the experimental data was taken as the apparent diffusion coefficient of the steel. In this case, the $\mathrm{D}_{\text {app }}$ value estimated for the CrMo_690 steel grade was $2.5 \cdot 10^{-10}$ $\mathrm{m}^{2} / \mathrm{s}$, while the fit to the experimental data is shown in Figure $4 \mathrm{~b}$.

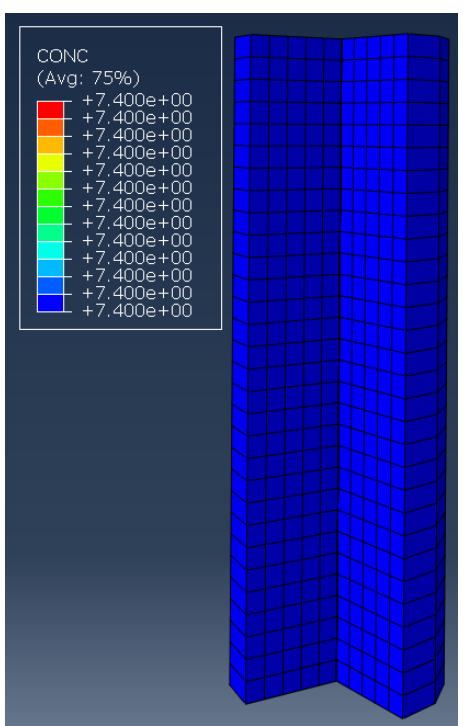

(a)

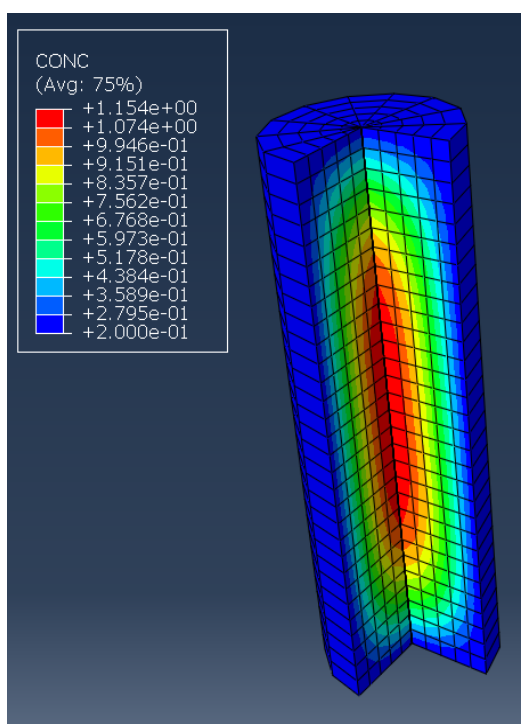

(b)

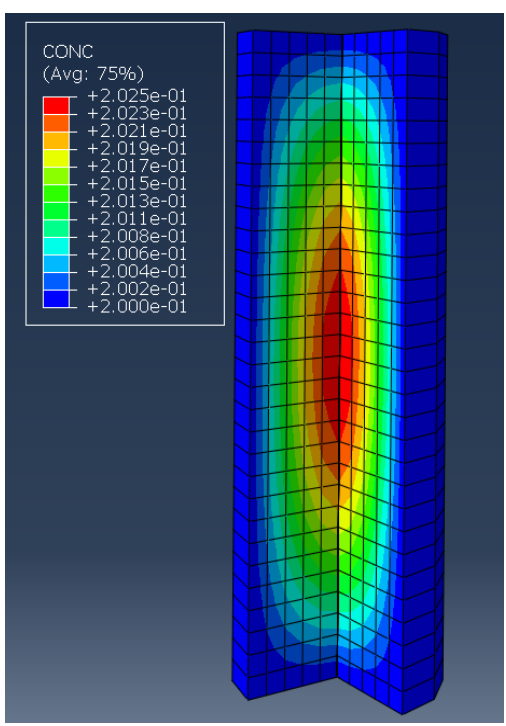

(c) 
Figure 5. Hydrogen distribution in the CrMo_690 steel in samples with $\mathrm{R}=5 \mathrm{~mm}$ and $\mathrm{L}=30 \mathrm{~mm}$. (a) Hydrogen concentration at the end of pre-charging $(7.4 \mathrm{ppm})$. (b) Initial concentration $(0.6 \mathrm{ppm})$ measured on the LECO DH603 analyser at the end of the cooling phase (BC1). (c) Residual concentration (0.2 ppm) after $17 \mathrm{~h}$ at $\mathrm{RT}(\mathrm{BC} 2)$.

The results obtained from the analysis of the hydrogen desorption curves are summarized in Table 4: $\mathrm{C}_{\mathrm{H} 0}$, corresponds to the first point of the desorption curve (hydrogen content at the end of the cooling phase following thermal pre-charge), $\mathrm{C}_{\mathrm{Hf}}$ is the residual hydrogen content or hydrogen strongly trapped in the steel microstructure, i.e. the hydrogen content after sufficiently long exposure time at room temperature $\left(\mathrm{t}_{\mathrm{f}}\right)$, the diffusible hydrogen being the amount that is able to exit traps and diffuse out of the steel when sufficient time is available, $\mathrm{C}_{\mathrm{Hd}}=\mathrm{C}_{\mathrm{H} 0}-\mathrm{C}_{\mathrm{Hf}}$, and finally, $\mathrm{D}_{\text {app }}$ represents the diffusion coefficient.

Table 4. Initial $\left(\mathrm{C}_{\mathrm{H} 0}\right)$, residual $\left(\mathrm{C}_{\mathrm{Hf}}\right)$ and diffusible $\mathrm{C}_{\mathrm{Hd}}=\left(\mathrm{C}_{\mathrm{H} 0}-\mathrm{C}_{\mathrm{Hf}}\right)$ hydrogen contents, along with apparent diffusion coefficients measured in the different steel grades.

\begin{tabular}{|c|c|c|c|c|c|}
\hline \multirow{2}{*}{ Steel grade } & \multicolumn{4}{|c|}{ From experimental LECO analyzer } & FEM analysis \\
\cline { 2 - 6 } & $\begin{array}{c}\mathrm{C}_{\mathrm{H} 0} \\
{[\mathrm{ppm}]}\end{array}$ & $\begin{array}{c}\mathrm{C}_{\mathrm{Hf}} \\
{[\mathrm{ppm}]}\end{array}$ & $\begin{array}{c}\mathrm{t}_{\mathrm{f}} \\
{[\mathrm{h}]}\end{array}$ & $\begin{array}{c}\mathrm{C}_{\mathrm{Hd}}=\left(\mathrm{C}_{\mathrm{Ho}-} \mathrm{C}_{\mathrm{Hf}}\right) \\
{[\mathrm{ppm}]}\end{array}$ & $\begin{array}{c}\mathrm{D}_{\text {app }} \\
{\left[\mathrm{m}^{2} / \mathrm{s}\right]}\end{array}$ \\
\hline 42CrMo4_700 & 1.20 & 0.25 & 120 & 0.95 & $4.2 \cdot 10^{-10}$ \\
\hline 42CrMo4_650 & 1.20 & 0.45 & 169 & 0.75 & $2.5 \cdot 10^{-10}$ \\
\hline 2.25Cr1Mo_690 & 0.60 & 0.20 & 17 & 0.4 & $2.5 \cdot 10^{-10}$ \\
\hline 2.25Cr1Mo_600 & 1.30 & 0.60 & 48 & 0.7 & $8.0 \cdot 10^{-11}$ \\
\hline 2.25Cr1Mo0.3V_720 & 4.20 & 4.00 & 220 & 0.2 & $2 \cdot 10^{-11}$ \\
\hline 2.25Cr1Mo0.3V_650 & 3.80 & 3.40 & 368 & 0.4 & $8 \cdot 10^{-12}$ \\
\hline
\end{tabular}

As regards the results shown in Table 4, it is worth noting that $\mathrm{V}$-added grades always absorb more hydrogen and desorb hydrogen more slowly than $\mathrm{V}$-free steels $(42 \mathrm{CrMo} 4$ and $2.25 \mathrm{Cr} 1 \mathrm{Mo})$, giving rise to the lowest apparent diffusion coefficients. Moreover, in the three studied steels, the diffusion coefficient significantly increases with increasing tempering temperature, as the microstructure has a lower density of traps and strong traps $[26,27]$. In order to establish a comparison between V-free and V-added steels, CrMo_690 and CrMoV_650 steel grades were compared. We were able to confirm that the hydrogen diffusion coefficient measured in the CrMo_690 is 30 times higher than that measured in the CrMoV_650. Fine vanadium carbides precipitated in the course of the tempering treatment are known to be very strong microstructural hydrogen traps $[17,28,29,30]$.

\subsection{Fatigue crack growth curves}

The curves representing the fatigue crack growth rate $(\mathrm{da} / \mathrm{dN})$ versus the stress intensity factor range $(\Delta \mathrm{K})$ obtained for the six steel grades at room temperature in air are shown in Figure 6. All data between 30 and 
$90 M P a \sqrt{m}$ show a good fit to the Paris fatigue law, while the Paris law coefficients, $\mathrm{C}$ and $\mathrm{m}(\mathrm{da} / \mathrm{dN}=\mathrm{C}$ $\left.\Delta \mathrm{K}^{\mathrm{m}}\right)$, as well as the corresponding $\mathrm{R}^{2}$ determination coefficient are given in Table 5.

The fatigue crack growth curves of the hydrogen-charged specimens likewise obtained at room temperature using different test frequencies are shown in Figure 7. These curves are also compared with those determined for the uncharged specimens. The acceleration effect in the fatigue crack growth rate due to the presence of internal hydrogen was only noted when the test frequency was lower than $10 \mathrm{~Hz}$ (in the case of 42CrMo4_700 below $1 \mathrm{~Hz})$, this effect being more significant under the lowest frequencies $(0.1$ and 0.05 $\mathrm{Hz}$ ), as was to be expected according to the previously cited papers $[6,7,9]$.

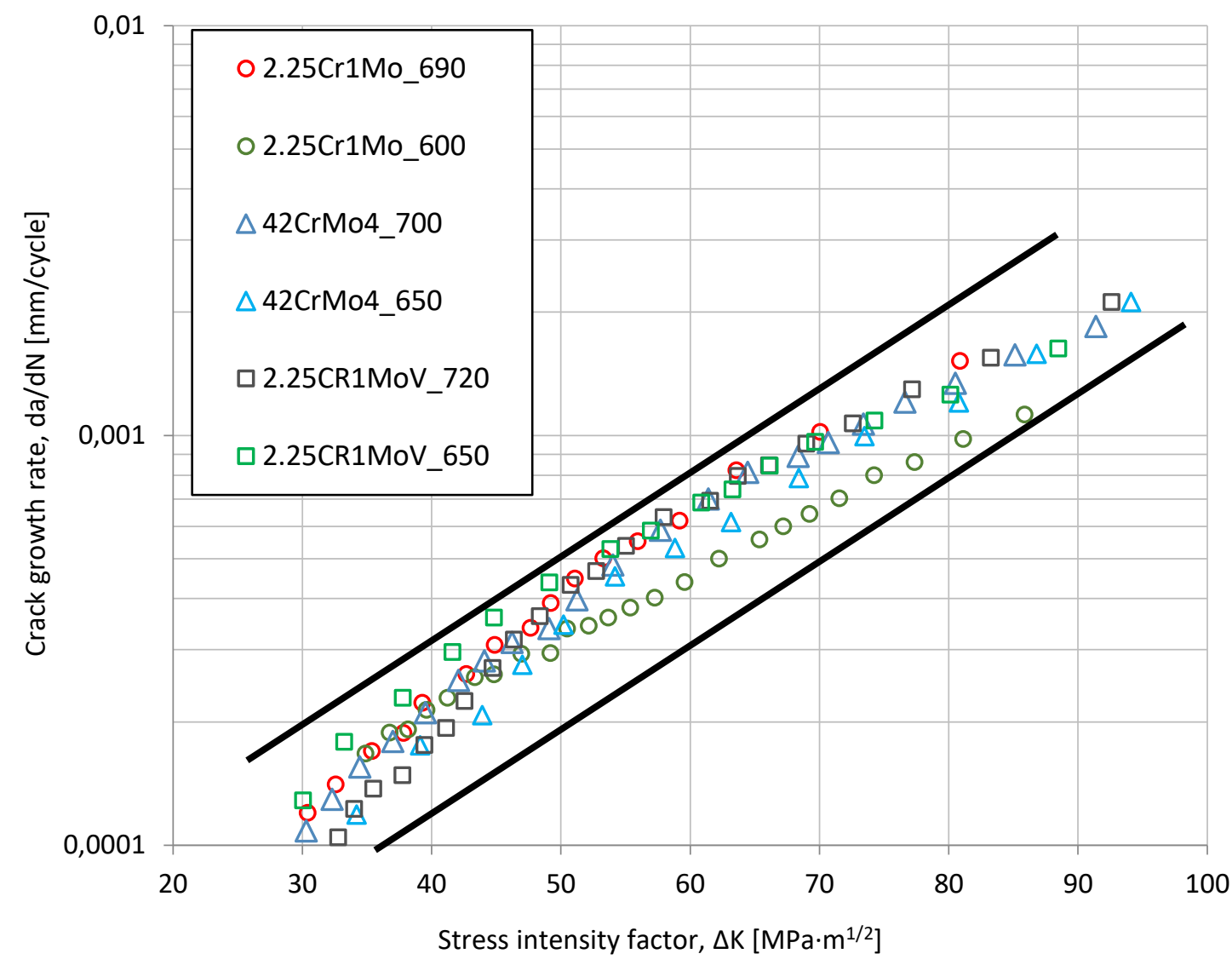

Figure 6. da/dN- $\Delta \mathrm{K}$ curves of uncharged specimens of all the studied steels $(10 \mathrm{~Hz}$ and $\mathrm{R}=0.1)$.

Table 5. Paris law parameters $(10 \mathrm{~Hz}$ and $\mathrm{R}=0.1)$

\begin{tabular}{|c|c|c|c|}
\hline \multirow{2}{*}{ Steel Grade } & \multicolumn{2}{|c|}{ Paris coefficients } & \multirow{2}{*}{$\mathrm{R}^{2}$} \\
\cline { 2 - 3 } & $\mathrm{da} / \mathrm{dN}=\mathrm{C} \cdot \Delta \mathrm{K}^{\mathrm{m}}(\mathrm{m} / \mathrm{c}, \mathrm{MPa} \sqrt{m})$ & $\mathrm{m}$ \\
\hline 42CrMo4_700 & $2,0 \mathrm{E}-08$ & 2,6 & 0,998 \\
\hline 42CrMo4_650 & $7,0 \mathrm{E}-09$ & 2,8 & 0,996 \\
\hline 2.25Cr1Mo_690 & $1,0 \mathrm{E}-08$ & 2,6 & 0,997 \\
\hline 2.25Cr1Mo_600 & 1,0E-07 & 2,1 & 0,989 \\
\hline 2.25Cr1MoV_720 & 4,0E-09 & 2,9 & 0,995 \\
\hline 2.25Cr1MoV_650 & 6,0E-08 & 2,3 & 0,998 \\
\hline
\end{tabular}



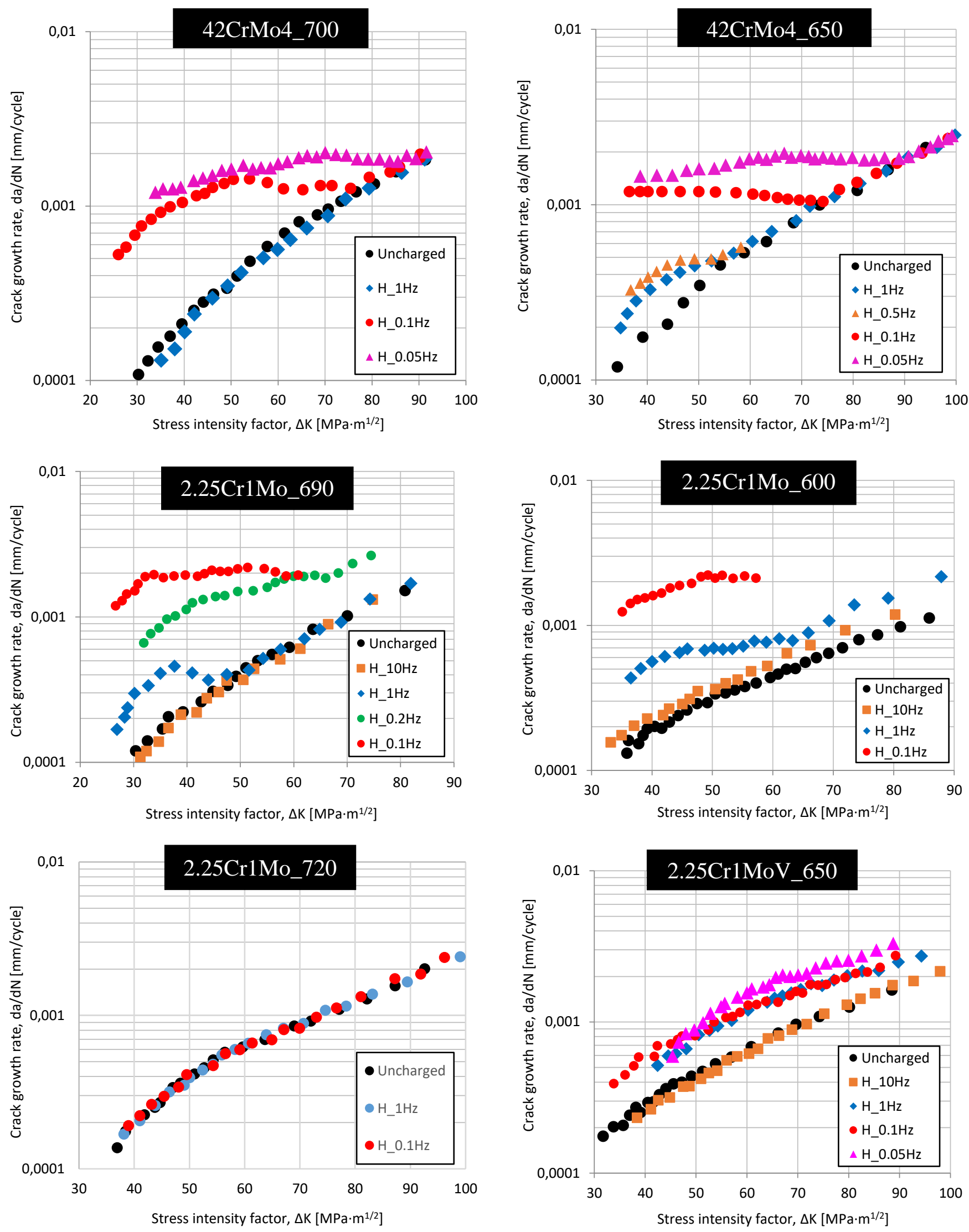

Figure 7. $\mathrm{da} / \mathrm{dN}-\Delta \mathrm{K}$ curves of $\mathrm{CrMo}(\mathrm{V})$ grades at $\mathrm{R}=0.1$ and different test frequencies. 
Figure 8 shows the fatigue curves obtained for all the studied steel grades tested with internal hydrogen using the lowest test frequency $(0.1 \mathrm{~Hz})$ compared with the fatigue behaviour obtained for the same steels in air. The ratio between the hydrogen crack growth rate $(\mathrm{da} / \mathrm{dN})_{\mathrm{H}}$ measured with hydrogen pre-charged specimens under the lowest frequency $(0.1 \mathrm{~Hz})$ and the crack growth rate obtained with uncharged specimens $(\mathrm{da} / \mathrm{dN})_{\mathrm{NoH}}$ is plotted against the applied $\Delta \mathrm{K}$ in Figure 9. This last factor is an indicator of hydrogen embrittlement susceptibility under cyclic loads. It is worth noting that the aforementioned acceleration ratio is the highest at low $\Delta \mathrm{K}$ values $(\Delta \mathrm{K}=25-35 \mathrm{MPa} \vee \mathrm{m})$. On the other hand, the crack growth acceleration ratio under internal hydrogen was much lower in the $\mathrm{V}$-added steels, although the internal hydrogen content in this steel was the highest (Table 4).

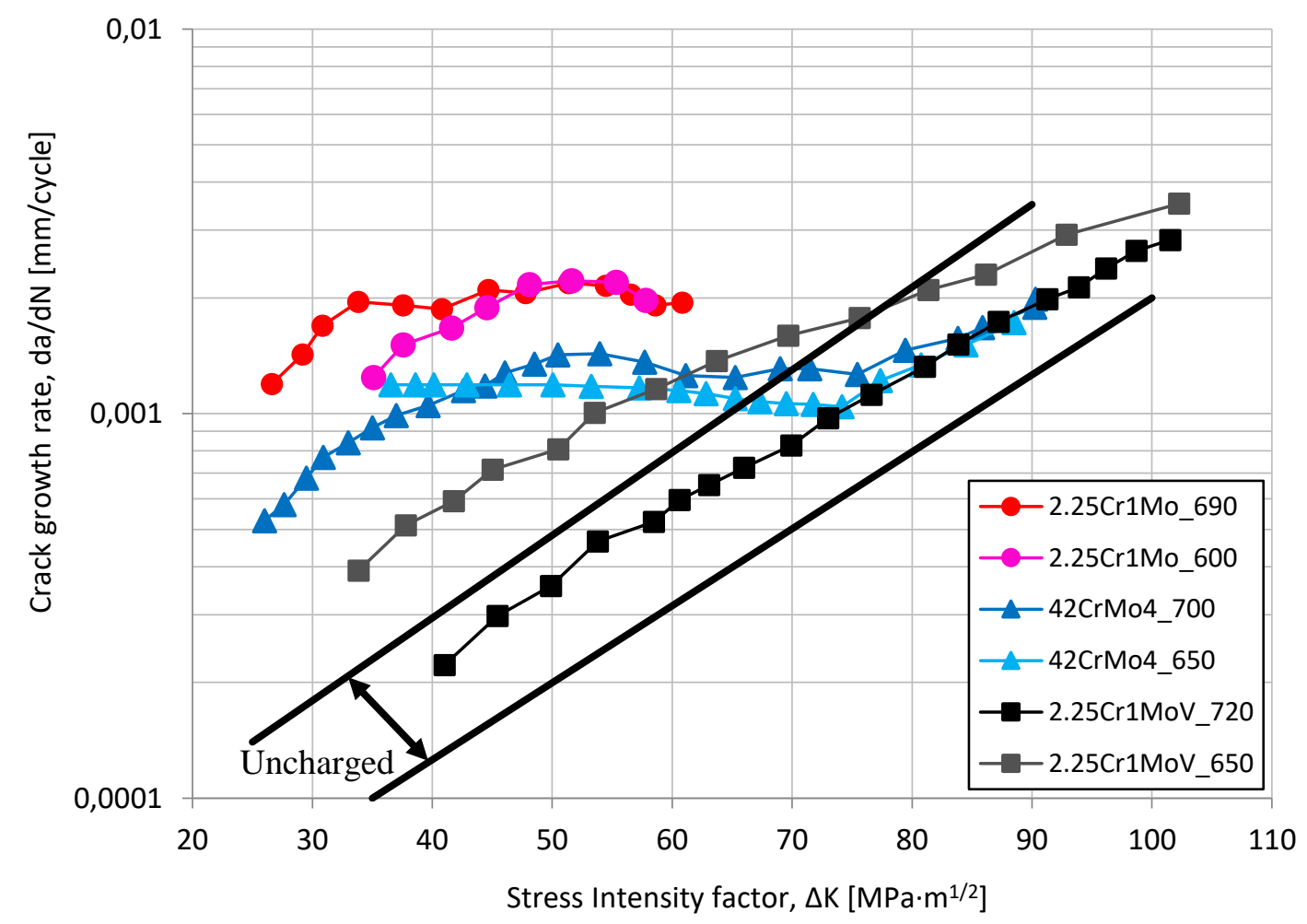

Figure 8. da/dN- $\Delta \mathrm{K}$ curves of $\mathrm{H}$ pre-charged specimens tested at $0.1 \mathrm{~Hz}$. 


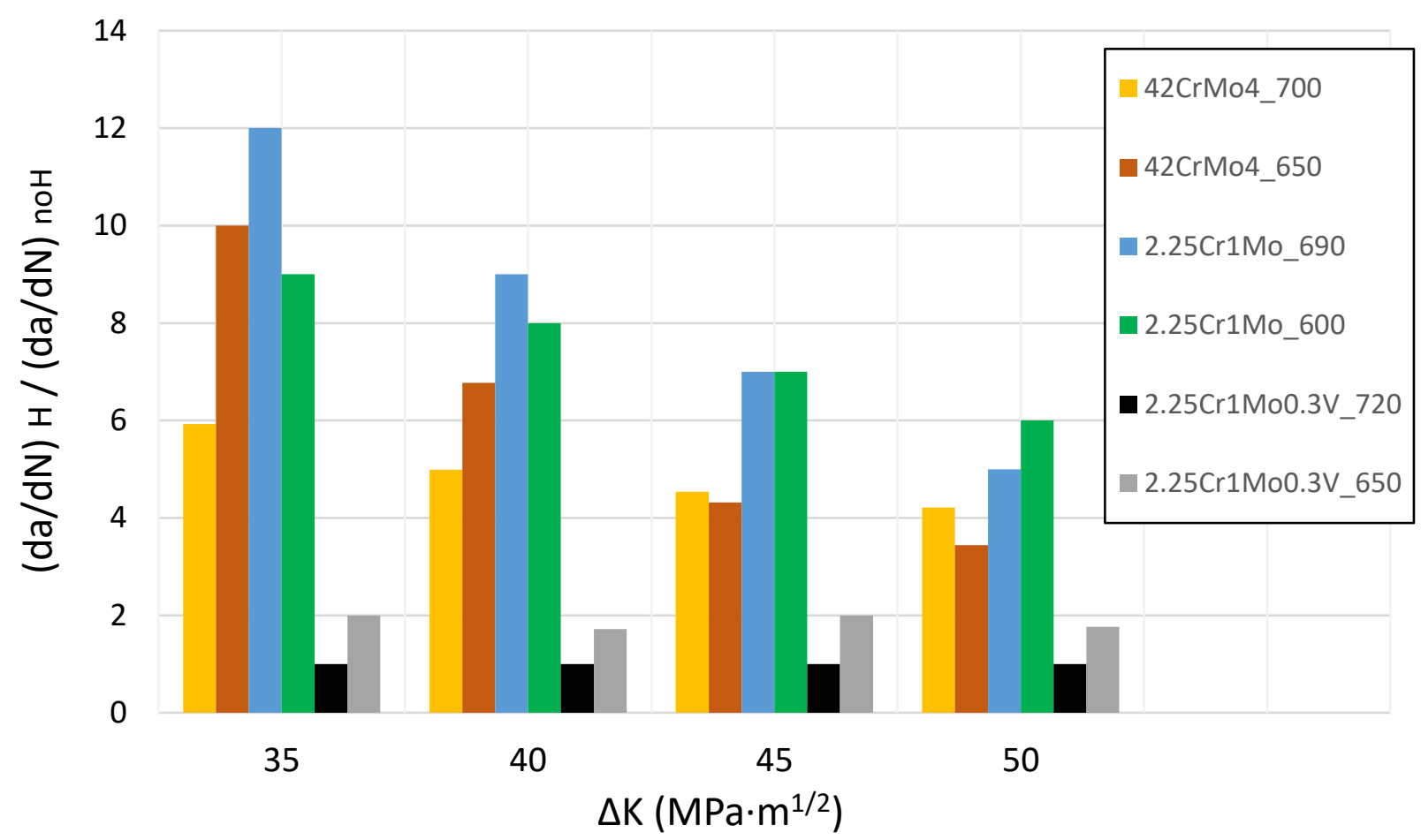

Figure 9. Fatigue crack growth acceleration factor due to internal hydrogen. $\mathrm{R}=0.1$ and $\mathrm{f}=0.1 \mathrm{~Hz}$.

\subsection{Fracture surfaces}

The fracture surfaces of the fatigued CT specimens were analysed under the scanning electron microscope, the most relevant features of which are shown in Figures 10,11 and 12. As already stated, the most relevant differences were noted at the lowest test frequencies $(0.1 \mathrm{~Hz})$ and low $\Delta \mathrm{K}$ values $(25-35 \mathrm{MPa} \sqrt{\mathrm{m}})$. Hence, only the failure surfaces of these specimens at the appropriate locations are shown.

Ductile fatigue striations (white arrows) perpendicular to the crack propagation direction are frequently observed in the specimens of the $42 \mathrm{CrMo} 4$ grades tested in air. However, they were much harder to find on the specimens tested with internal hydrogen, where the PRHIC micromechanism (plasticity-related hydrogen-induced cracking) is the most relevant and characteristic feature (Figure $10 \mathrm{a}, \mathrm{b}$ ). Other authors $[6,7,31]$ have already pointed out the difficulty of observing fatigue striations in fatigue tests performed in the presence of hydrogen. It is well known that hydrogen enhances localized slip in the crack front, in accordance with the HELP model, the crack tip hardly opens in the fatigue cycle, and hence striations due to ductile stretching are barely marked on the resultant failed surface.

A similar observation related to the presence of striations in the uncharged specimens and the PRHIC micromechanism in those samples tested with internal hydrogen can also be made in the case of the 2.25Cr1Mo grades, although some small areas of intergranular fracture (IG) are also visible in the specimens tested with internal hydrogen (Figure 11). Intergranular failure mechanisms were also detected by [32,33,34] in the fatigue failure surfaces of quenched and tempered $2.25 \mathrm{Cr} 1 \mathrm{Mo}$ steel, which could be also related to possible segregation of $\mathrm{P}$ and other residual elements such as $\mathrm{Sn}, \mathrm{Sb}$ and, As into prior austenite grain boundaries.

However, no significant change in micromechanism was observed in the uncharged and hydrogen charged $\mathrm{V}$-added 2.25Cr1Mo grades. Fatigue striations were observed in all cases and the most noteworthy difference between the uncharged and hydrogen pre-charged specimens was the presence of secondary cracks and small 
areas with a quasi-cleavage appearance in the specimens of these $\mathrm{V}$-added grades tested with internal hydrogen (Figure 12).

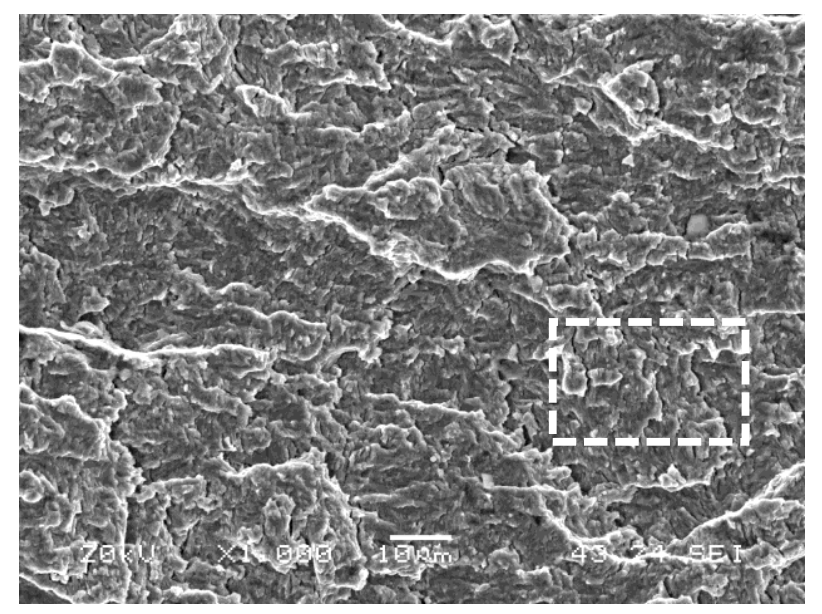

Uncharged (1000x)



H_0.1Hz (1000x)

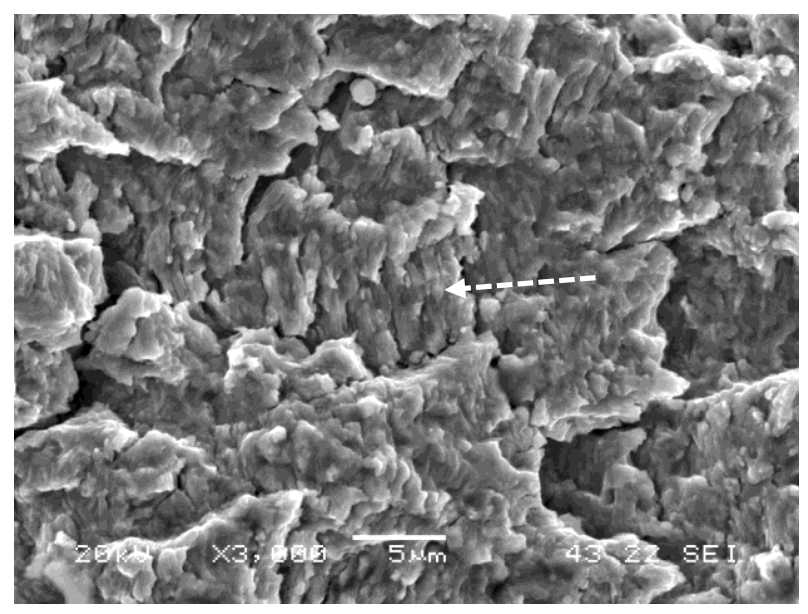

Uncharged (3000x)

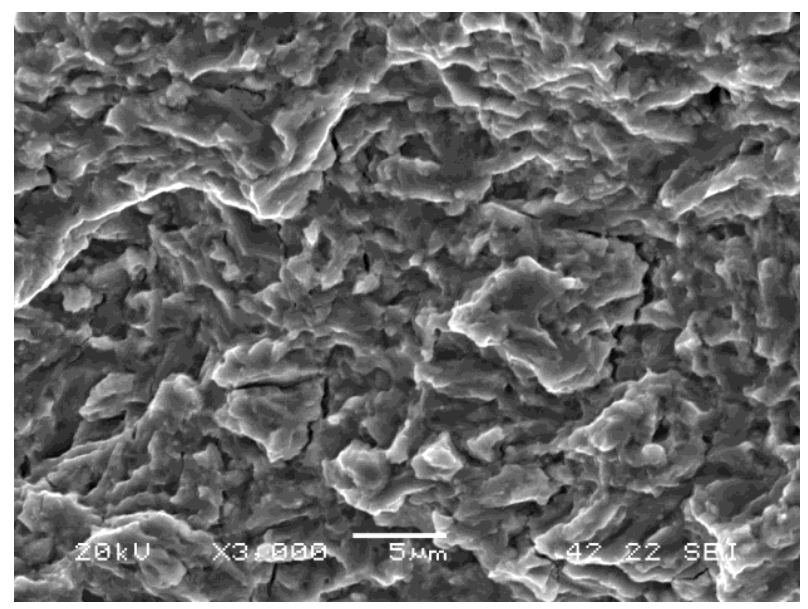

H_0.1Hz (3000x)

(a) 42CrMo4_700
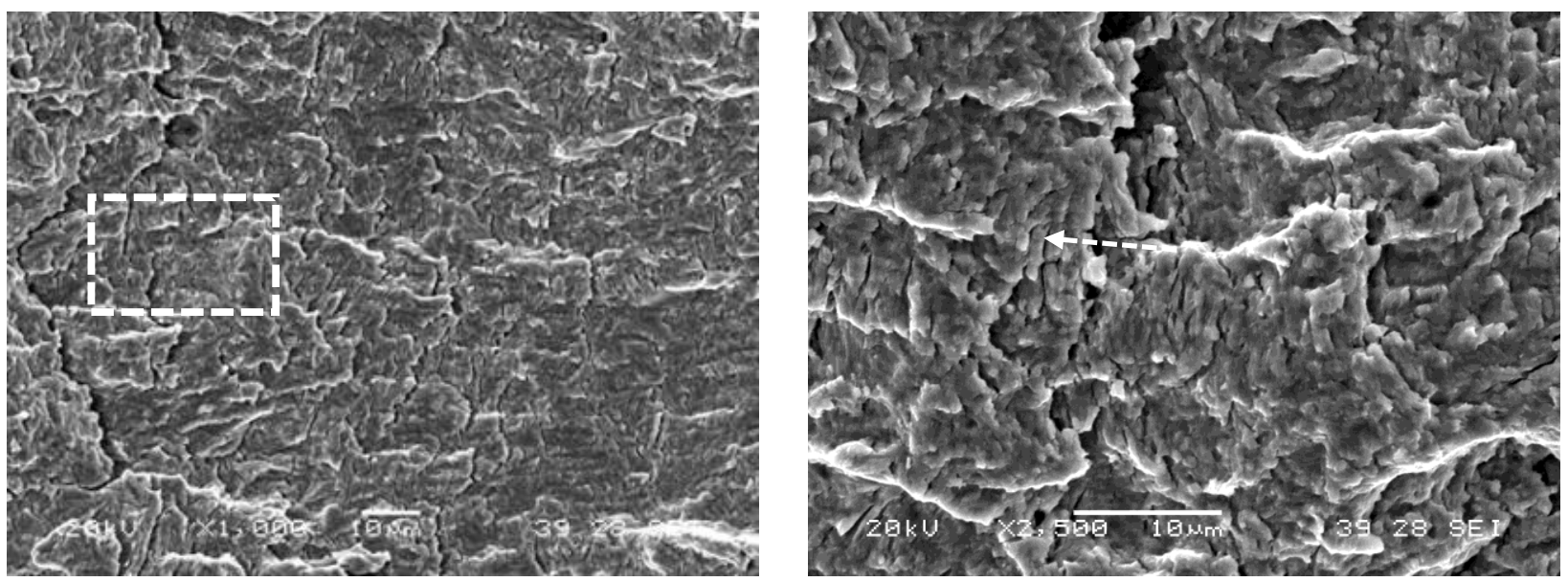


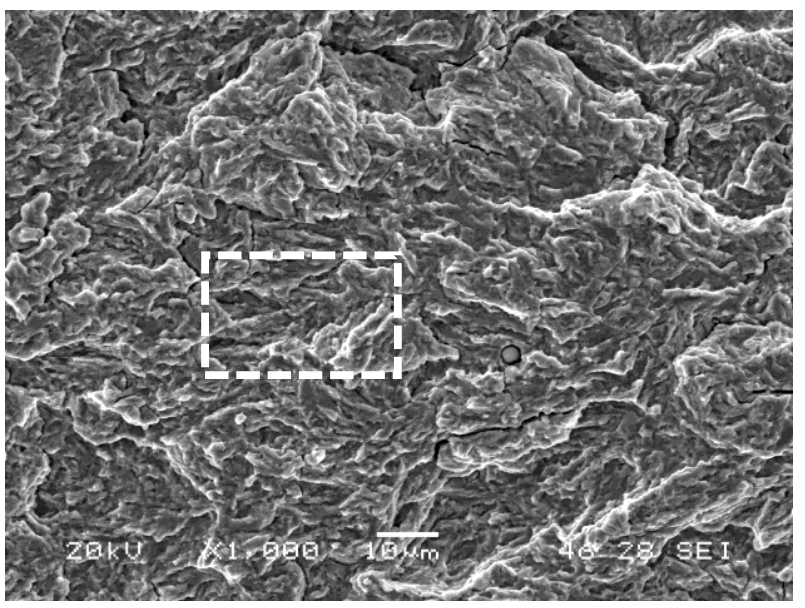

H_0.1Hz (1000x)

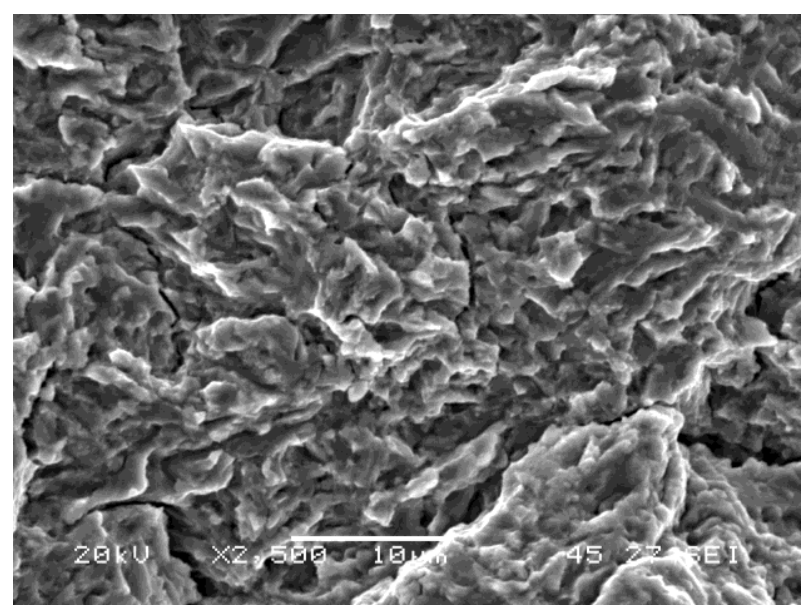

H_0.1Hz (2500x)

(b) 42CrMo4_650

Figure 10. Fatigue failure surfaces of uncharged $(10 \mathrm{~Hz})$ and $\mathrm{H}$ pre-charged $42 \mathrm{CrMo} 4$ specimens $(0.1 \mathrm{~Hz})$. $\Delta \mathrm{K}=25-35 \mathrm{MPa} \sqrt{\mathrm{m}}$. 42CrMo4_700 (a) and 42CrMo4_650 (b).

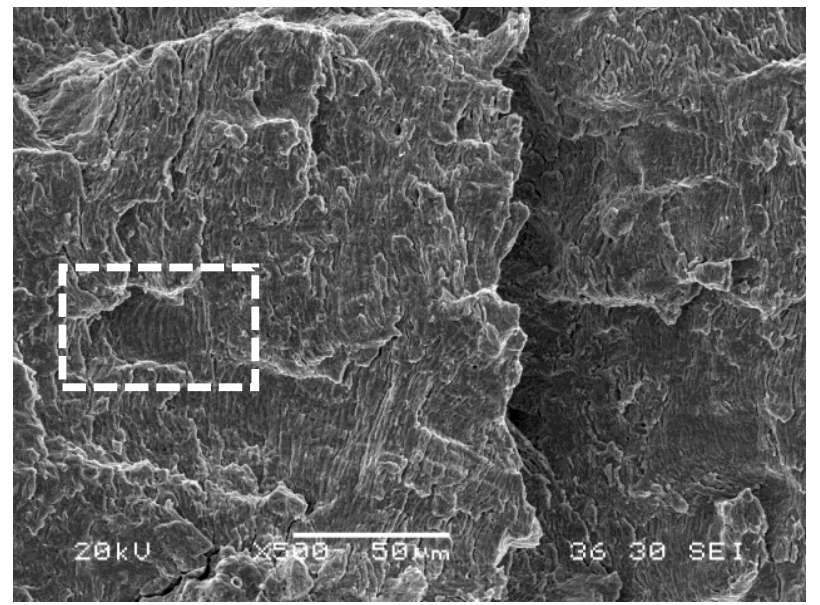

Uncharged (500x)

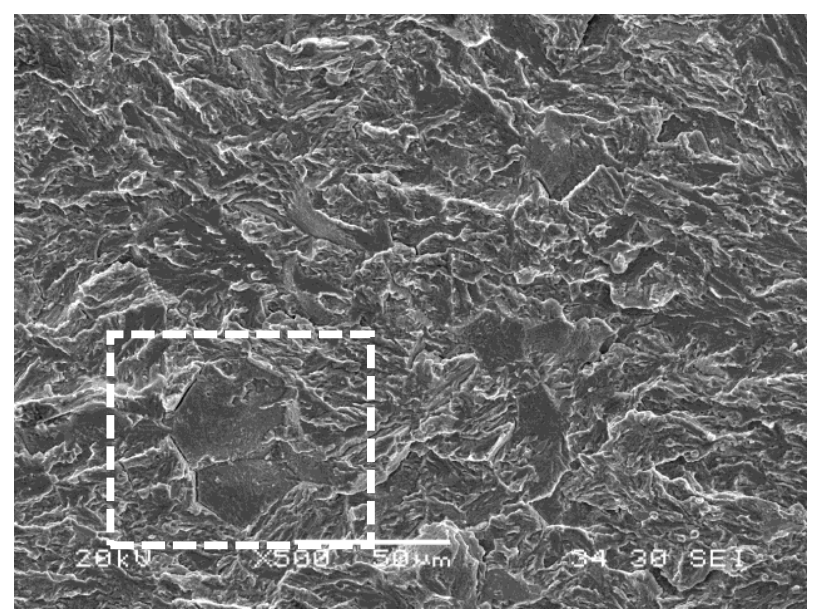

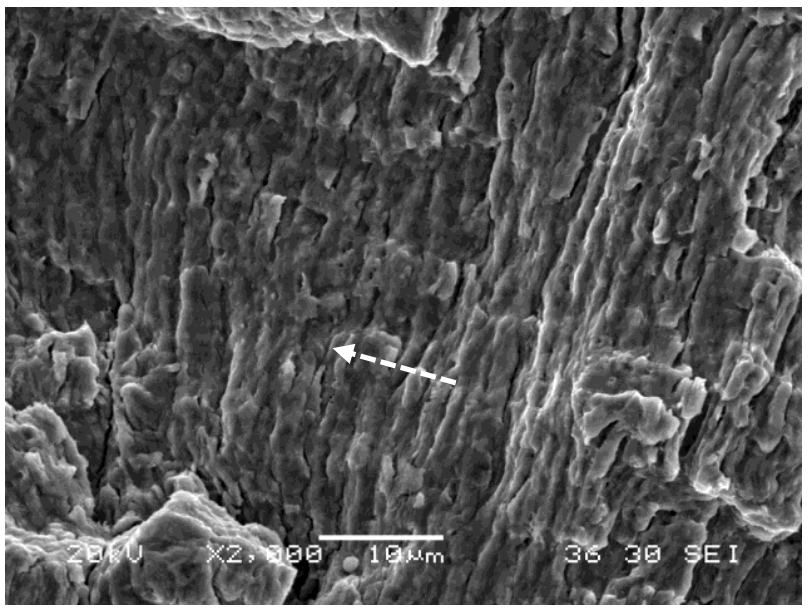

Uncharged (2000x)

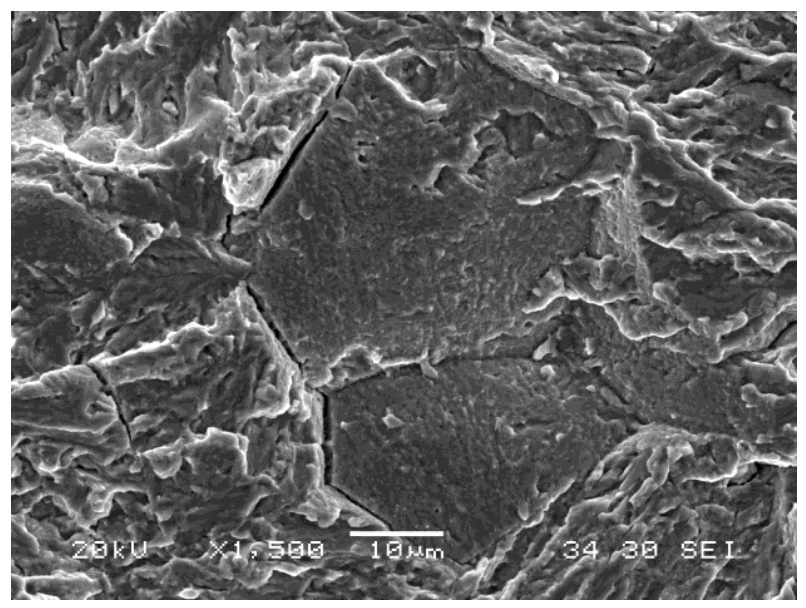




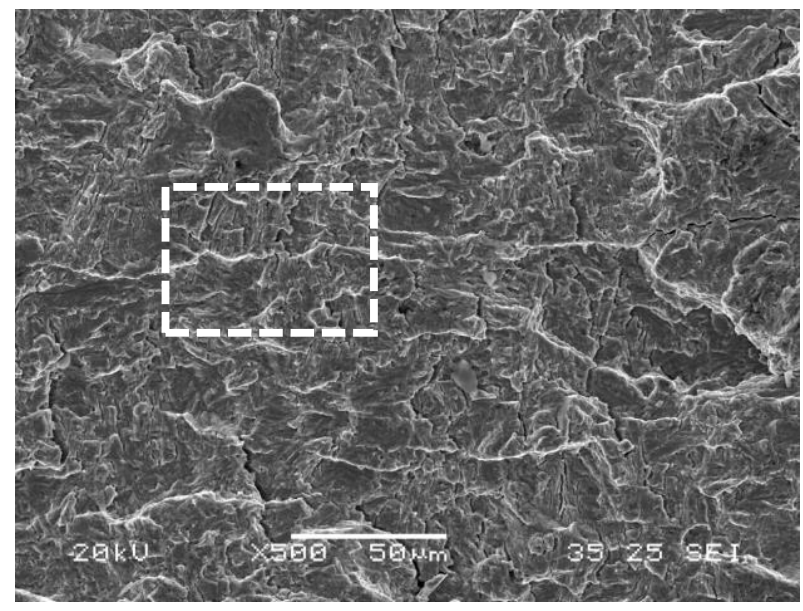

Uncharged (500x)

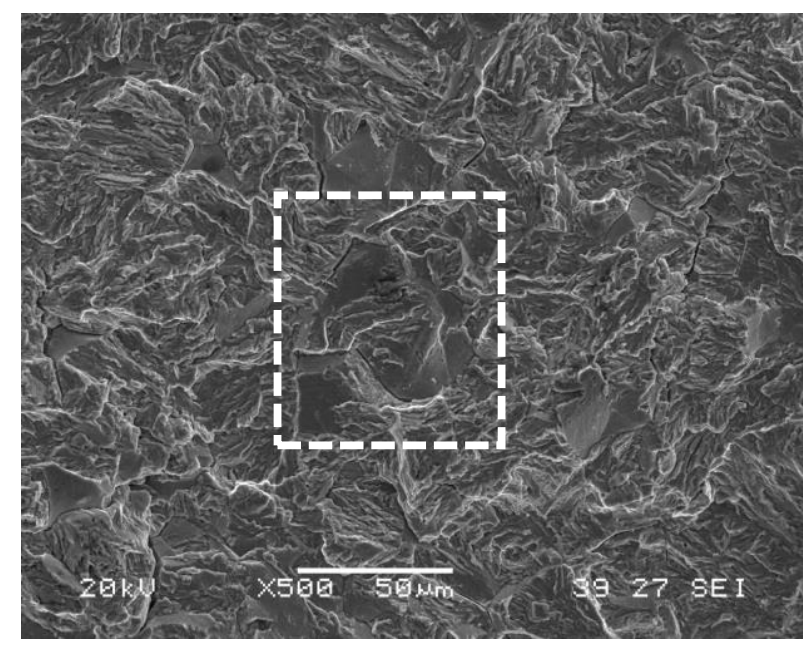

H_0.1Hz (500x)

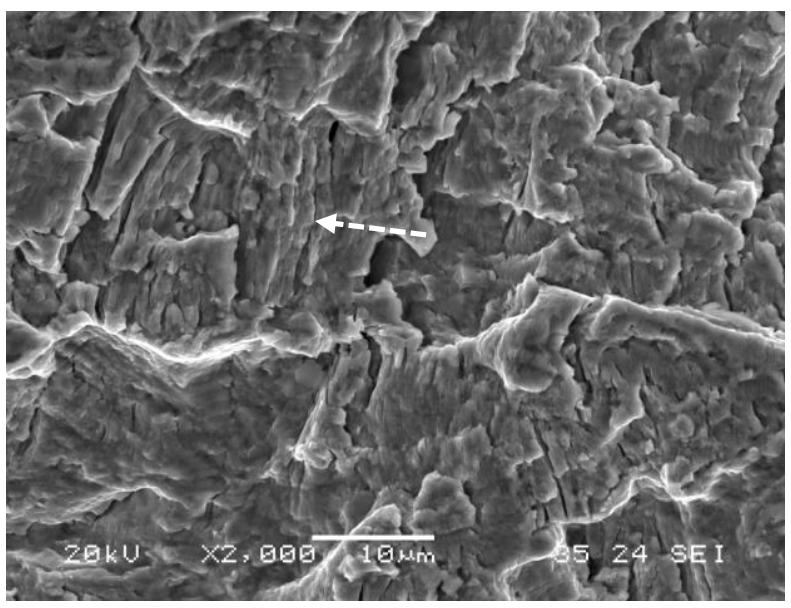

Uncharged (2000x)

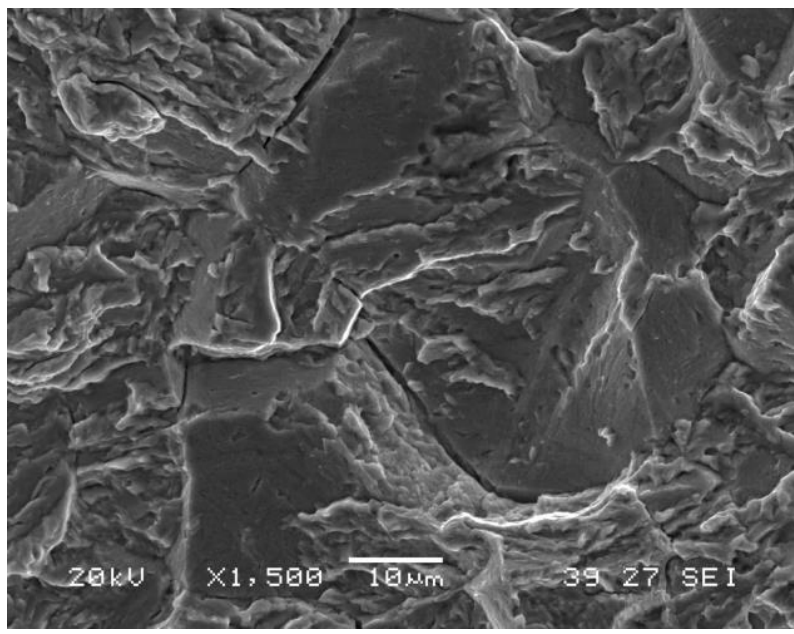

H_0.1Hz (1500x)

(b) 2.25Cr1Mo_600

Figure 11. Fatigue failure surfaces of uncharged $(10 \mathrm{~Hz})$ and $\mathrm{H}$ pre-charged $2.25 \mathrm{Cr} 1 \mathrm{Mo}$ specimens $(0.1 \mathrm{~Hz})$. $\Delta \mathrm{K}=25-35 \mathrm{MPa} \sqrt{\mathrm{m}}$. 2.25Cr1Mo_690 (a) and 2.25Cr1Mo_600 (b). 


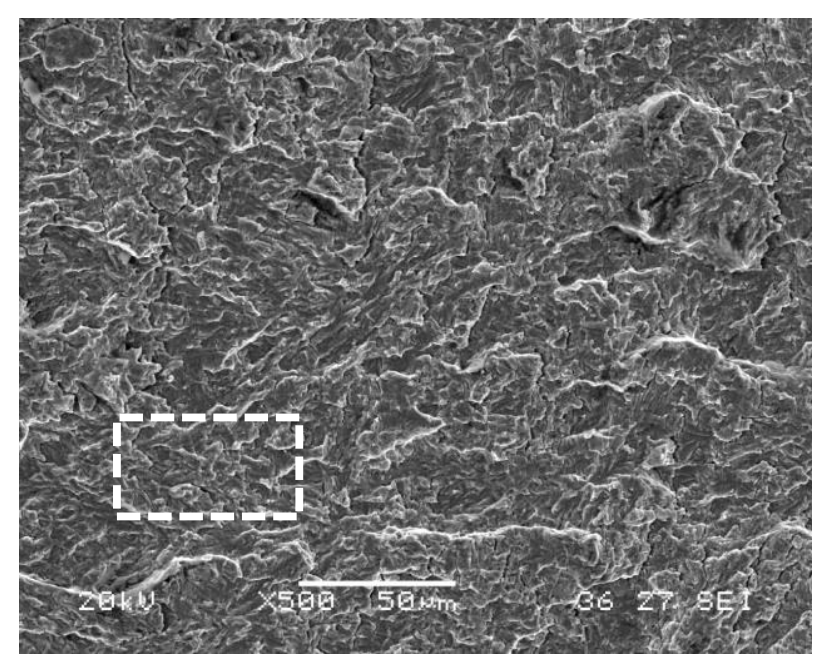

Uncharged (500x)

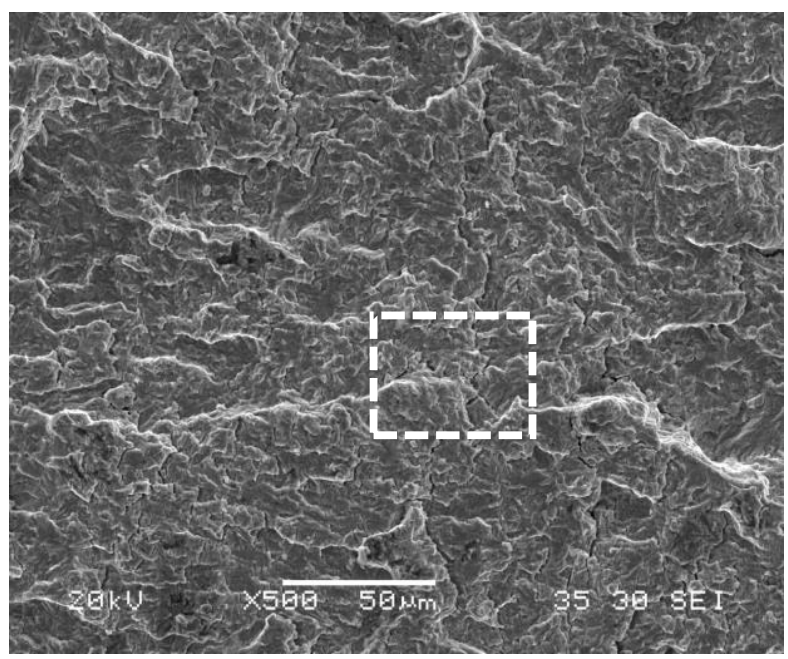

H_0.1Hz (500x)

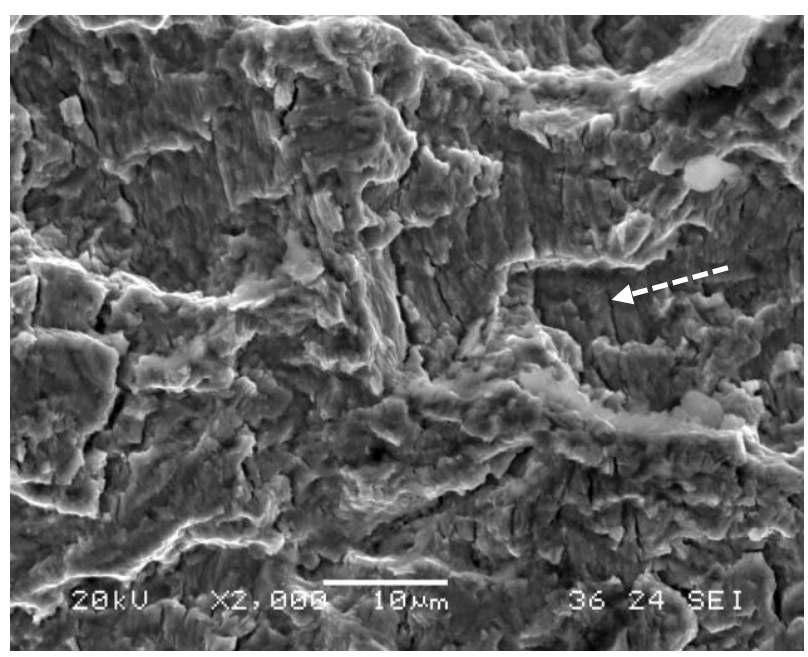

Uncharged (2000x)

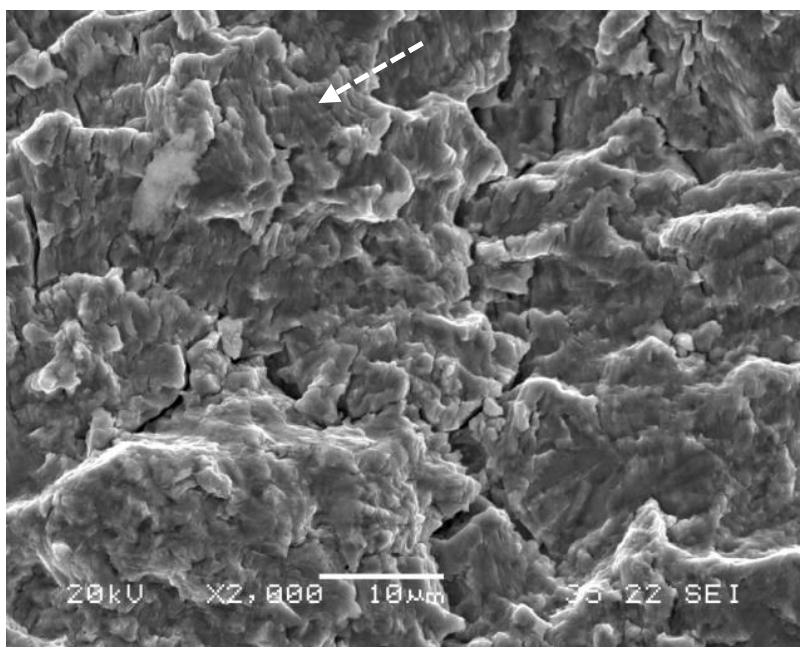

H_0.1Hz (2000x)

(a) $2.25 \mathrm{Cr} 1 \mathrm{MoV} \_720$

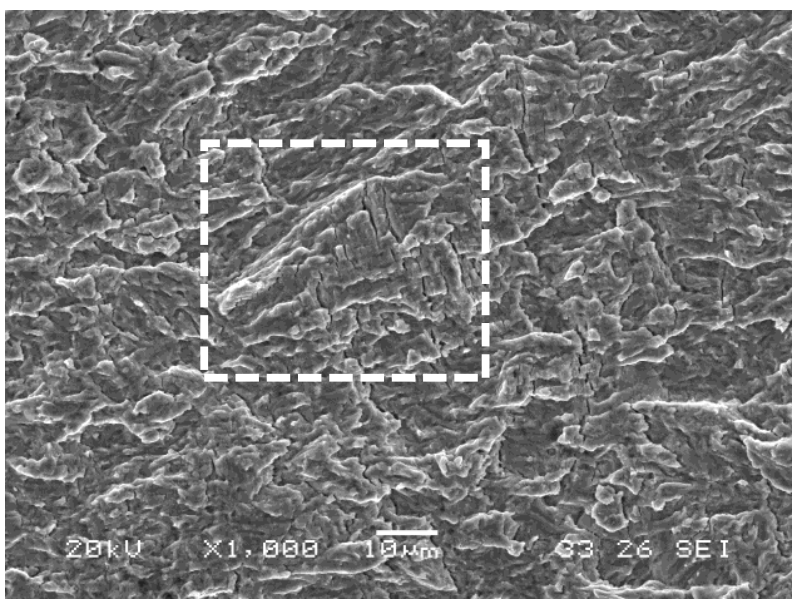

Uncharged (1000x)

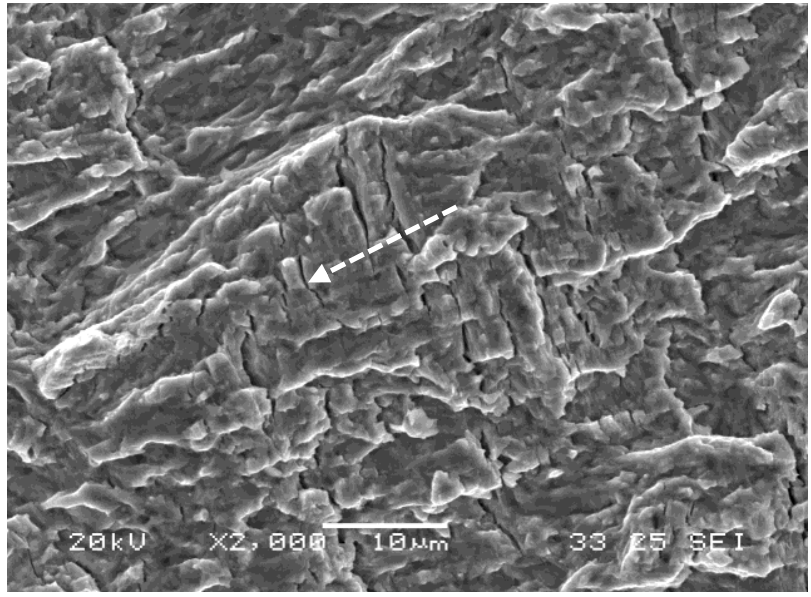

Uncharged (2000x) 


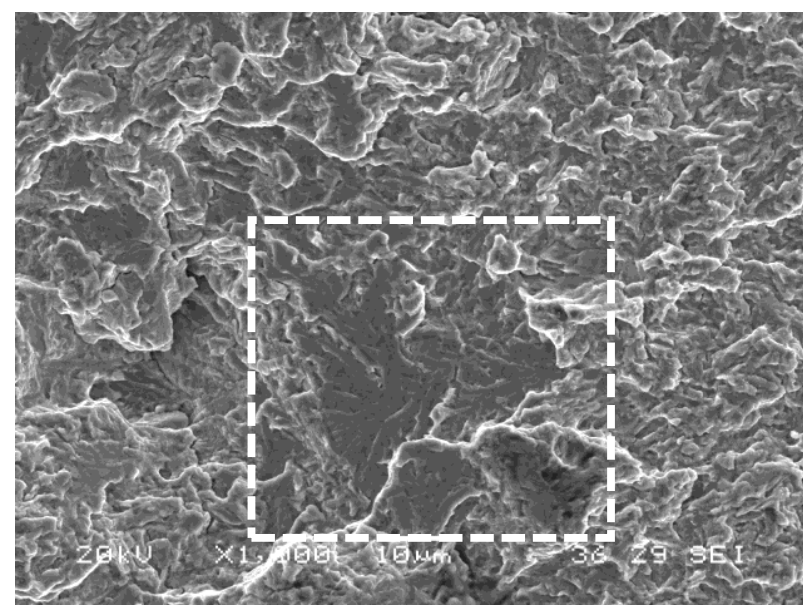

H_0.1Hz (1000x)

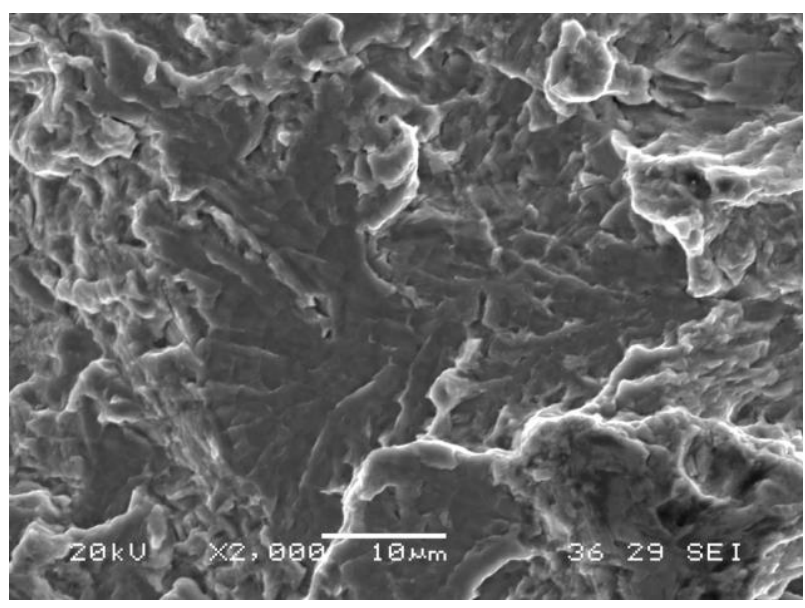

H_0.1Hz (2000x)

(b) $2.25 \mathrm{Cr} 1 \mathrm{MoV} \_650$

Figure 12. Fatigue failure surfaces of uncharged $(10 \mathrm{~Hz})$ and $\mathrm{H}$ pre-charged $2.25 \mathrm{Cr} 1 \mathrm{MoV}$ specimens $(0.1$ $\mathrm{Hz}$ ). $\Delta \mathrm{K}=25-35 \mathrm{MPa} \sqrt{ }$ m. 2.25Cr1MoV_720 (a) and 2.25Cr1MoV_650 (b).

\section{Discussion}

In order to discuss the fatigue results obtained in this study, it should be recalled that, when a mechanical load is applied to a pre-cracked and hydrogen pre-charged CT specimen, hydrogen located in the surroundings of the crack tip will diffuse up to the process zone located just ahead of the crack tip (reversibly trapped by dislocations in the plastic strained zone and also driven by the high hydrostatic stress existing in the crack front), where hydrogen atoms will accumulate. This gives rise to hydrogen enhanced localized plasticity (HELP) mechanisms and also to the embrittlement phenomenon (usually hydrogen enhanced decohesion, HEDE). Hence, the influence of the test frequency on the fatigue crack growth rate will depend on the time that hydrogen has to relocate in each fatigue load cycle to reach a critical concentration in the aforementioned process region (see Figure 13).

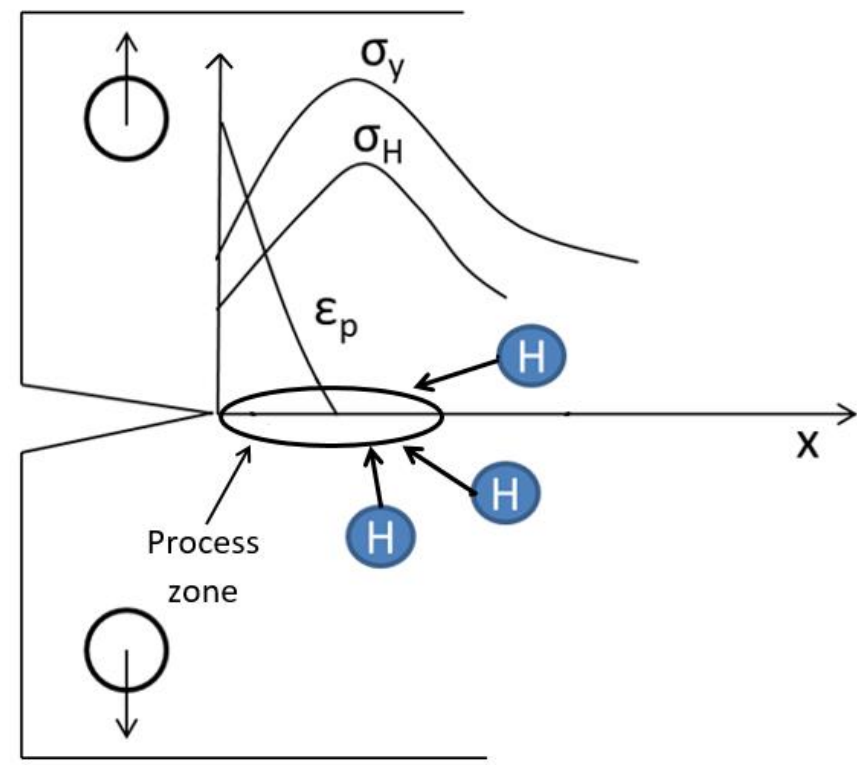

Figure 13. Hydrogen accumulation into the process zone ahead of an opened crack tip. $\sigma_{\mathrm{y}}, \sigma_{\mathrm{H}}$ and $\varepsilon_{\mathrm{p}}$ are respectively the opening stress, hydrostatic stress and plastic strain. 
Thus, the hydrogen crack growth acceleration factor observed under low fatigue frequencies, lower than 10 $\mathrm{Hz}$ (see Figures 7, 8 and 9), might be explained via the effective diffusion distance, $\mathrm{x}$, available for the movement of hydrogen atoms during the fatigue cycle, which can be estimated from Fick's second law, Equation 5.

$$
x=\sqrt{D t}
$$

$\mathrm{D}$ being the apparent hydrogen diffusion coefficient in the steel and $\mathrm{t}$, the time available in each fatigue cycle $(\mathrm{t}=1 / \mathrm{f})$. Table 6 shows the effective hydrogen diffusion distances calculated for each steel grade versus the applied test frequency.

Table 6. Effective diffusion distance $(\mu \mathrm{m})$

\begin{tabular}{|c|c|c|c|c|}
\hline \multirow[b]{2}{*}{ Steel grade } & \multirow[b]{2}{*}{$\mathrm{D}_{\mathrm{app}}\left[\mathrm{m}^{2} / \mathrm{s}\right]$} & $10 \mathrm{~Hz}$ & $1 \mathrm{~Hz}$ & $0.1 \mathrm{~Hz}$ \\
\hline & & $\begin{array}{c}0.1 \\
\text { s/cycle }\end{array}$ & $\begin{array}{c}1 \\
\text { s/cycle }\end{array}$ & $\begin{array}{c}10 \\
\text { s/cycle }\end{array}$ \\
\hline 42CrMo4_700 & $4.2 \cdot 10^{-10}$ & $6 \mu \mathrm{m}$ & $20 \mu \mathrm{m}$ & $65 \mu \mathrm{m}$ \\
\hline 42CrMo_650 & $2.5 \cdot 10^{-10}$ & $5 \mu \mathrm{m}$ & $16 \mu \mathrm{m}$ & $50 \mu \mathrm{m}$ \\
\hline 2.25Cr1Mo_690 & $2.5 \cdot 10^{-10}$ & $5 \mu \mathrm{m}$ & $16 \mu \mathrm{m}$ & $50 \mu \mathrm{m}$ \\
\hline 2.25Cr1Mo_600 & $8 \cdot 10^{-11}$ & $3 \mu \mathrm{m}$ & $9 \mu \mathrm{m}$ & $28 \mu \mathrm{m}$ \\
\hline 2.25Cr1MoV_720 & $2 \cdot 10^{-11}$ & $1 \mu \mathrm{m}$ & $4 \mu \mathrm{m}$ & $14 \mu \mathrm{m}$ \\
\hline 2.25Cr1MoV_650 & $8 \cdot 10^{-12}$ & $1 \mu \mathrm{m}$ & $3 \mu \mathrm{m}$ & $9 \mu \mathrm{m}$ \\
\hline
\end{tabular}

When the test frequency is high $(10 \mathrm{~Hz})$, the fatigue cycle load time is low, and thus, the hydrogen diffusion distances are also very low. Hence, hydrogen accumulation in the crack tip region is barely significant and the fatigue crack growth rate does not differ from the value determined without hydrogen in air. However, when the test frequency decreases, effective hydrogen diffusion distances increase significantly, reaching values, that allow considerable hydrogen accumulation in the crack tip process region. In this case, hydrogen diffusion will be coupled with the crack growth rate and hydrogen atoms will diffuse in and out of the process zone in every fatigue cycle, thereby enabling the existence of the so-called embrittled process zone due to hydrogen accumulation. This fact would explain the increase in the crack growth rate observed in the $42 \mathrm{CrMo} 4$ and 2.25Cr1Mo grades cycled at low test frequencies.

It was also observed in Figures 7 and 8 that the fatigue crack growth rate under internal hydrogen tends towards the value obtained under testing in air above a given da/dN (or $\Delta \mathrm{K}$ ) value. This change in behaviour may also be explained as a result of competition between the fatigue crack growth rate and hydrogen diffusion rate: for $\mathrm{da} / \mathrm{dN}$ crack growth rates higher than a certain value, the crack passes the process zone at the crack tip before hydrogen concentrates in this region, as the crack grows much faster than hydrogen diffusion to the crack tip. Similar observations have previously been reported by other researchers $[6,7,18,20,34,35]$.

Returning to the $2.25 \mathrm{Cr} 1 \mathrm{MoV}$ steel, the hydrogen effect was notably lower in these grades (in fact no hydrogen effect was detected in the $2.25 \mathrm{Cr} 1 \mathrm{Mo} \_720$ grade). It is worth noting that the effective diffusion distances in the $\mathrm{V}$-added steels tested at $0.1 \mathrm{~Hz}$ were nearly similar to those observed in the CrMo steels tested at $1 \mathrm{~Hz}$. Moreover, diffusible hydrogen, $\mathrm{C}_{\mathrm{Hd}}$, is also the lowest in this steel (Table 4). As stated previously, the existence of submicrometric vanadium carbides existing in the $\mathrm{V}$-added steel grades have the capacity to strongly retain hydrogen, thereby reducing the apparent diffusion coefficient and, hence, their effective diffusion distances.

Figure 8 clearly shows that $2.25 \mathrm{Cr} 1 \mathrm{Mo}$ grades have the highest fatigue crack growth rates in the presence of internal hydrogen under low frequency testing $(0.1 \mathrm{~Hz})$, as the accumulation of hydrogen in the process zone of this steel gives rise to some intergranular decohesion, which can be appreciated in the fractographic analysis (Figure 11). On the other hand, the fatigue crack growth rate of the $2.25 \mathrm{Cr} 1 \mathrm{MoV}$ grades under the same conditions were the lowest: in this case, because of the beneficial effects due to the aforementioned fine precipitation of vanadium carbides during the tempering stage of this steel. 
It should also be noted that, from a certain $\Delta \mathrm{K}$ value (or a certain crack propagation rate, $\mathrm{da} / \mathrm{dN}$ ), a kind of "plateau" in the crack propagation rate was sometimes detected (Figures 7 and 8). It was found that, as K (or $\Delta \mathrm{K}$ ) increases, local stresses increase and hydrogen is more strongly attracted by the crack tip process zone, thereby facilitating embrittlement. However, as previously stated, as $\Delta \mathrm{K}$ increases, so does $\mathrm{da} / \mathrm{dN}$, and the crack may grow faster than the hydrogen diffusion rate towards the crack tip, while the acceleration due to hydrogen accumulation may decrease. This two-fold, yet opposing hydrogen effect may explain the "plateau" observed in some da/dN versus $\Delta \mathrm{K}$ curves in Figures 7 and 8. A plateau like this is typically referred to in the scientific literature when a phenomenon of stress corrosion cracking (SCC) or hydrogen assisted cracking (HAC) is present [36]. Under these circumstances, if the applied stress intensity factor in the fatigue cycle exceeds a threshold value, $\mathrm{K}_{\mathrm{ISCC}}$, the crack extends at a constant growth rate regardless of the applied $\Delta \mathrm{K}$. A similar "plateau" in the $\mathrm{da} / \mathrm{dN}$ versus $\Delta \mathrm{K}$ results was also observed in tests performed with external hydrogen in [35], as well as in fatigue tests performed with internal hydrogen in [18,20,34] using electrochemically or thermally pre-charged specimens.

Another possible explanation underlying this phenomenon could be the progressive loss of hydrogen the specimens underwent in the course of the fatigue tests. However, the results of our fatigue tests always correspond to specimens with internal hydrogen, as tests performed on the CrMo steels were always interrupted after no more than 8-10 hours under the lowest test frequencies, thereby ensuring that significant diffusible hydrogen was still present in the fatigue specimen at the end of each fatigue test (see also Figure 4 a,b). Furthermore, this point is not an issue with $\mathrm{CrMoV}$ steel grades due to their much lower apparent diffusion coefficients and hence, much longer times needed to lose internal hydrogen (Figure $4 \mathrm{c}$ ). Moreover, the maximum time duration of the fatigue tests performed with these steel grades under the lowest frequency was approximately 50 hours.

\section{Conclusions}

Hydrogen desorption data experimentally obtained after hydrogen thermal pre-charging in a high-pressure hydrogen reactor were used along with finite element simulation of hydrogen diffusion in cylindrical samples to determine the apparent hydrogen diffusion coefficients of different structural quenched and tempered steel grades. Diffusion coefficients always increase with increasing tempering temperature, while the addition of vanadium strongly reduces the hydrogen diffusion coefficient due to the trapping effect of vanadium carbides.

The presence of internal hydrogen leads to an increase in the crack propagation rate in the CrMo steel grades, this effect increasing as the test frequency applied in the fatigue test decreases. This behaviour can be explained by assuming that hydrogen embrittlement is controlled by the diffusion of hydrogen atoms toward the process zone existing in the advancing crack tip. As the test frequency decreases, hydrogen diffusion distances in the fatigue cycle increase and hydrogen concentration in the process zone can reach a critical value for the decohesion of internal boundaries, martensite blocks and packets or prior austenitic grain boundaries.

The fatigue behaviour of the CrMoV steel grade in the presence of internal hydrogen was greatly improved and the effect of frequency was nearly negligible in this case, as the microstructure of this steel grade presents uniform dispersion of submicrometric vanadium carbides, which behave as strong traps for hydrogen, thereby considerably reducing its mobility.

Finally, hydrogen pre-charged CT specimens gradually lose hydrogen during the fatigue test. Therefore, it is important to control the total duration of tests in order to appreciate the effect of internal hydrogen on the steel fatigue crack growth rate.

\section{Acknowledgements}

The authors would like to thank the Spanish Ministry of Economy and Competitiveness for the support received to carry out research project MAT2014-58738-C3 (SAFEHIDROSTEEL) and also to the Principado de Asturias government for the financing support given to the IDI/2018/000134 project. 


\section{References}

[1] C. San Marchi, B.P. Somerday, SAND2008-1163: Technical reference on hydrogen compatibility of materials, Sandia Report, Sandia National Laboratories, 2008.

[2] L. Briottet, R. Batisse, G. de Dinechin, P. Langlois, and L. Thiers, "Recommendations on X80 steel for the design of hydrogen gas transmission pipelines", Int. J. Hydrogen Energy, 37, 11, 2012, 9423-9430.

[3] M. Wang, E. Akiyama, and K. Tsuzaki, "Effect of hydrogen on the fracture behavior of high strength steel during slow strain rate test", Corrosion Science, 49, 11, 2007, 4081-4097.

[4] E. Akiyama, M. Wang, S. Li, Z. Zhang, Y. Kimura, N. Uno, K. Tsuzaki, "Studies of evaluation of hydrogen embrittlement property of high-strength steels with consideration of the effect of atmospheric corrosión", Metallurgical and Materials Transactions, vol. 44A, 2013, 1290-1300

[5] R.P. Gangloff, B.P. Sommerday Edit., Gaseous hydrogen embrittlement of materials in energy technologies, 2012.

[6] Y. Murakami, S. Matsuoka, Effect of hydrogen on fatigue crack growth of metals, Eng. Fract. Mech., 77, 2010, 1926-1940.

[7] S. Matsuoka H. Tanaka, N. Homma, Y. Murakami, Influence of hydrogen and frequency on fatigue crack growth behavior of Cr-Mo steel, Int. J of Fracture, 168, 2011, 101112.

[8] J. Yamabe, H. Matsunaga, Y. Furuya, S. Hamada, H. Itoga, M. Yoshikawa, E. Takeuchi, S. Matsuoka, Qualification of chromium-molybdenum steel based on the safety factor multiplier method in CHMC1-2014, Int. J. Hydrogen Energy,40, 2015, 719-728.

[9] A. Macadre, M. Artamonov, S. Matsuoka, J. Furtado, Effects of hydrogen pressure and test frquency on fatigue crack growth properties of Ni-Cr-Mo steel candidate for storage cyclinder of a $70 \mathrm{MPa}$ hydrogen filling station, Engineering Fracture Mechanics, 78, 2011, 3196-3211

[10] R.L. Amaro, N. Rustagi, K.O. Findley, E.S. Drexler, A.J. Slifka, Modelling the fatigue crack growth of X100 pipeline steel in gaseous hydrogen, Int. J of Fatigue, 59, 2014, 262-271.

[11] A. J. Slifka, E.S. Drexler, N.E. Nanninga, Y.S. Levy, J.D. McColskey, R.L. Amaro, A. E. Stevenson, Fatigue crack growth of two pipeline steels in a pressurized hydrogen environment, Corrosion Science, 78, 2014, 313-321.

[12] B.P. Somerday, P. Sofronis, K.A. Nibur, C. San Marchi, R. Kirchheim, Elucidating the variables affecting accelerated fatigue crack growth of steels in hydrogen gas with low oxygen concentrtions, Acta Materialia, 61, 2013, 6153-6170.

[13] K. Tazoe, S. Hamada, H. Noguchi, Fatigue crack growth behaviour of JIS SMC440 steel near fatigue thershold in ) MPa hydrogen gas environment, Int. J. of Hydrogen Energy, 42, 2017, 13158-13170.

[14] L. Briottet, R. Batisse, G. de Dinechin, P. Langlois, L. Thiers, Recommendations on X-80 steel for the design of hydrogen gas transmission pipelines, Int. J. of Hydrogen Energy, 37, 2012, 9423-9430.

[15] Z. Hua, X. Zhang, J. Zheng, C. Gu, T. Cui, Y. Zhao, W. Oeng, Hydrogen-enhanced fatigue life analysis of Cr-Mo steel high-pressure vessels, Int. J. Hydrogen Energy, 42, 2017, 12005-12014.

[16] B.P. Somerday, J.A. Campbell, K.L. Lee, J.A. Ronevich, C. San Marchi, Enhancing safety of hydrogen containment components through materials testing under in-service conditions, Int. J. Hydrogen Energy, 42, 2017, 7314-7321.

[17] S. Pillot, L. Coudreuse, Hydrogen-induced disbonding and embrittlement of steels used in petrochemical refinining, Woodhead Publishing Limited, 2012.

[18] A. Macadre, H. Yano, S. Matsuoka, J. Furtado, The effect of hydrogen on the fatigue life of Ni-Cr-Mo steel envisaged for use as a storage cylinder for a $70 \mathrm{MPa}$ hydrogen station, Int. J. of Fatigue, 33, 2011, $1608-1619$

[19] J. Yamabe, T. Matsumoto, S. Matsuoka, Y. Murakami, A new mechanism in hydrogen-enhanced fatigue crack growth behaviour of a $1900 \mathrm{MPa}$ class high-strength steel, Int. J. of Fracture, 177, 2012, 141162.

[20] C. Colombo, G. Fumagalli, F. Bolzoni, G. Gobbi, L. Vergani, Fatigue behavior of hydrogen pre-charged low ally Cr-Mo steel, Int. J of Fatigue, 83, 2016, 2-9. 
[21] Y. Kondo, M. Kubota, K. Shimada, Hydrogen enhanced crack propagation of SCM440H low-alloy steel under long-term varying load, Eng. Fract. Mechanics, 77, 2010, 1963-1974.

[22] ASTM E647, Standard test method for measurement of fatigue crack growth rates, Annual Book of ASTM Standards, Vol. 03.01, (2015).

[23] G. Krauss, Steels: Processing, Structure and Performance, ASM International, 2005.

[24] J.P. Hirtz, Effects of hydrogen on the properties of iron and steel, Metallurgical Transactions 11A, 1980, 861-890.

[25] San Marchi C., Somerday B.P. Robinson S.L., Permeability, solubility and diffusivity of hydrogen isotopes in stainless steels at high gas pressures, Int. J. Hydrogen Energy, 32, 2007, 100-116

[26] N. Parvathavarthini, S. Saroja, R.K. Dayal, H.S. Khatak, Studies on hydrogen permeability of 2.25Cr1Mo ferritic steel: correlation with microstructure, Journal of Nuclear Materials, 288, 2001, 187-196.

[27] F. Fallahmohammadi, F. Bolzoni, G. Fumagalli, G. Re, G. Benassi, Hydrogen diffusion into three metallurgical microstructures of a C-Mn X65 and low alloy F22 sour service steel pipelines, International Journal of Hydrogen Energy, 39, 2014, 13300-13313.

[28] W. Hui, H. Zhang, Y. Zhang, X. Zhao, C. Shao, Effect of nickel on hydrogen embrittlement behavior of medium-carbon high strength steels, Materials Science \&Engineering A674, 2016, 615-625.

[29] J. Lee, T. Lee, Y.J. Kwon, D.J. Moon, J.Y. Yoo, C.S. Lee, Effect of vanadium carbides on hydrogen embrittlement of tempered martensitic steel, Met. Mater. Int., 22, 3, 2016, 364-372.

[30] H. Asahi, D. Hirakami, S. Yamasaki, Hydrogen trapping behavior of vanadium-added steel, ISIJ International, 43, 2003, 527-533.

[31] L. Briottet, I, Moro, M. Escot, J. Furtado, P. Bortot, G.M. Tamponi, J. Solin, G. Odemer, C. Blanc, E. Andrieu , Int. J. Hydrogen Energy, 40, 2015, 17021-17030.

[32] R.O. Rithchie, S. Suresh, C.M. Moss, Near-threshold fatigue crack growth in 2.25Cr-1Mo pressure vessel steel in air and hydrogen, J. of Engineering Materials and Technology, 102, 1980, 293-299.

[33] L.W. Tsay, C.C. Liu, Y.H. Chao, Y.H. Shieh, Fatigue crack propagation in $2.25 \mathrm{Cr}-1 \mathrm{Mo}$ steel weldments in air and hydrogen, Materials Science and Engineering A299, 2001, 16-26.

[34] P. Fassina, N.F. Brunella, L. Lazzari, G. Re, L. Vergani, A. Sciuccati, Effect of hydrogen and low temperature on fatigue crack growth of pipeline steels, Engineering Fracture Mechanics, 103, 2013, 10-25.

[35] L. Tau, S.L.I. Chan, C.S. Shin, Hydrogen enhanced fatigue crack propagation of bainitic and tempered martensitic steels, Corrosion Science, 38, 11, 1996, 2049-2060.

[36] R.H. Jones, Edit., Stress-corrosion cracking. Materials performance and evaluation, ASM International, (2017). 